\title{
Multidisciplinary approach to the treatment of invasive fungal infections in adult patients. Prophylaxis, empirical, preemptive or targeted therapy, which is the best in the different hosts?
}

\author{
Rafael Zaragoza' \\ Javier Pemán ${ }^{2}$ \\ Miguel Salavert ${ }^{3}$ \\ Ángel Viudes ${ }^{2}$ \\ Amparo Solé ${ }^{4}$ \\ Isidro Jarque ${ }^{5}$ \\ Emilio Monte ${ }^{6}$ \\ Eva Romá ${ }^{6}$ \\ Emilia Cantón ${ }^{7}$
}

'Servicio de Medicina Intensiva, Hospital Universitario Dr Peset, Valencia, Spain; ${ }^{2}$ Servicio de Microbiología;

${ }^{3}$ Unidad de Enfermedades Infecciosas;

${ }^{4}$ Unidad de Trasplante Pulmonar;

${ }^{5}$ Servicio de Hematología; ${ }^{6}$ Servicio de Farmacia; 'Unidad de Microbiología

Experimental, Centro de Investigación, Hospital Universitario La Fe Valencia, Spain
Correspondence: Rafael Zaragoza Servicio de Medicina Intensiva, Hospital Universitario Dr Peset, Av Gaspar Aguilar, 90, 46017 Valencia, Spain

$\mathrm{Tel}+34961622569$

Fax +3496162 250I

Email zaragoza_raf@gva.es

\begin{abstract}
The high morbidity, mortality, and health care costs associated with invasive fungal infections, especially in the critical care setting and immunocompromised host, have made it an excellent target for prophylactic, empiric, and preemptive therapy interventions principally based on early identification of risk factors. Early diagnosis and treatment are associated with a better prognosis. In the last years there have been important developments in antifungal pharmacotherapy. An approach to the new diagnosis tools in the clinical mycology laboratory and an analysis of the use new antifungal agents and its application in different clinical situations has been made. Furthermore, an attempt of developing a state of the art in each clinical scenario (critically ill, hematological, and solid organ transplant patients) has been performed, trying to choose the best strategy for each clinical situation (prophylaxis, pre-emptive, empirical, or targeted therapy). The high mortality rates in these settings make mandatory the application of early de-escalation therapy in critically ill patients with fungal infection. In addition, the possibility of antifungal combination therapy might be considered in solid organ transplant and hematological patients.
\end{abstract}

Keywords: invasive fungal infections, prophylaxis, empirical therapy, preemptive treatment, targeted therapy

\section{Introduction}

Hospital medicine has advanced greatly in the past few decades. Patients with complex medical and surgical disorders are surviving longer due to equally complex medical and surgical interventions, which often involve "collateral damage" by avoiding normal body defensive mechanisms.

Invasive fungal infections (IFIs) in adult patients, especially in the critical care setting, solid organ transplant (SOT), and hematological patients, have become an excellent target for prophylactic, empiric, and pre-emptive therapy interventions due to their increasing incidence, high morbidity and mortality rates, and associated health care costs. Early diagnosis and treatment are associated with a better prognosis. Although at present, the number of systemic antifungal agents has increased significantly, the choice of antifungal drug must be based on the individual characteristics of the patient, clinical scenario, and the presence of hemodynamic instability. A tailored therapy (de-escalation) must also be considered in some clinical situations.

Different possible strategies based on diagnoses stage has been described as prophylactic, empiric, pre-emptive and targeted antifungal therapy (Figure 1). Prophylactic treatment refers to the preventive administration of an antifungal agent to patients at risk of IFI without attributable signs and symptoms. Empiric treatment is defined 


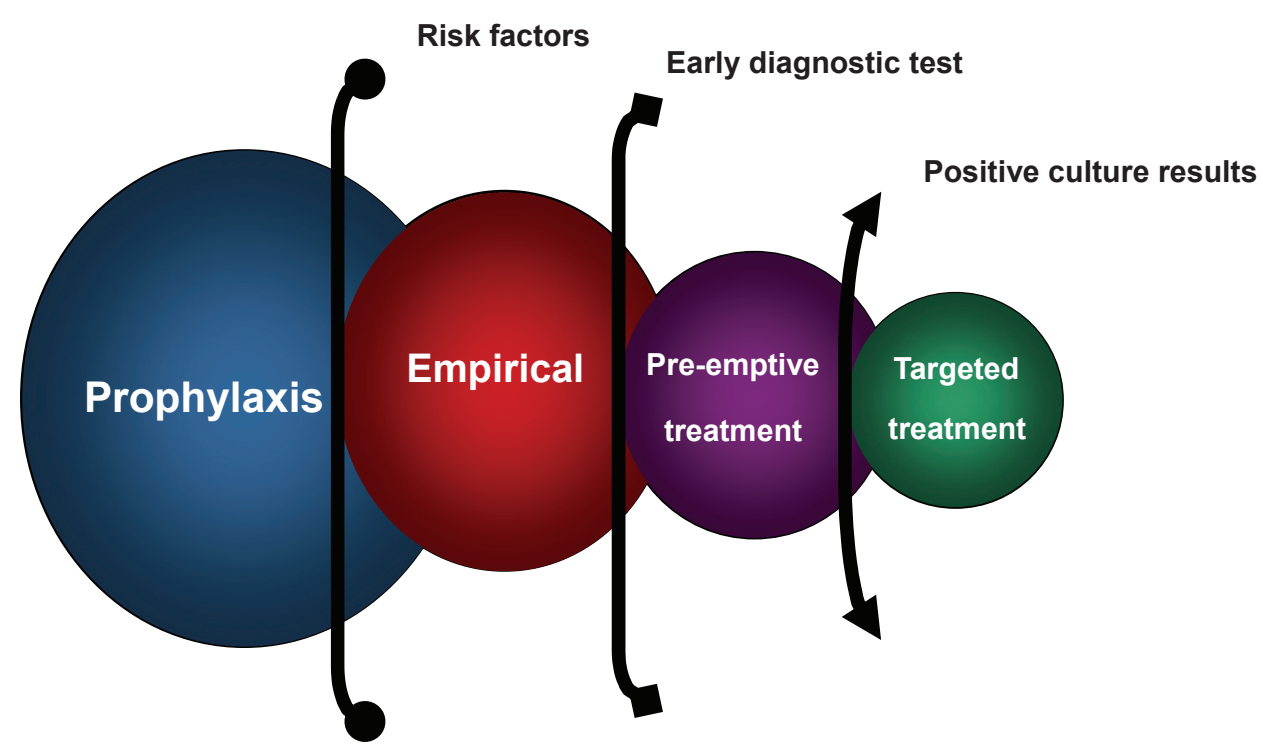

Figure I Different antifungal strategies for treatment in invasive fungal infections based on diagnostic stage.

as the initiation of antifungal treatment in patients at high risk of IFIs and established clinical signs and symptoms, but without microbiological documentation, whereas preemptive therapy is applied when the decision of treatment is based on early diagnostic test. Finally, targeted therapy needs a pathogen identification to be defined.

The aim of this multidisciplinary review was to analyze the best option for treating this special population of adults patients, describing the antifungal armamentarium, making an approach to the mycology laboratory diagnosis and finally developing a state of the art clinical scenario (critically ill, hematological and transplant patients) trying to choose the best strategy for each clinical situation (prophylaxis, empirical, pre-emptive, or targeted therapy).

\section{Role of the mycology laboratory in the antifungal therapy options Microbiological diagnosis for preventive treatment}

The incidence of IFIs has steadily increased in the past two decades. These infections represent an additional difficulty in the management of immunocompromised patients and are a contributory cause of death in allogeneic hematopoietic stem cell and SOT recipients and in patients undergoing intensive chemotherapy (Cordonnier et al 2006).

The high mortality associated with IFIs is partly correlated to the difficulties of making an early diagnosis due to the nonspecific clinical features and the low sensitivity of microscopy, histological examination, conventional radiology and cultures of specimens obtained from at-risk patients (Hope et al 2005). However, improved survival can be obtained by earlier initiation of antifungal therapy. The time period between the biological onset of a fungal infection and the appearance of clinical signs and symptoms represents a window of opportunity that, if identified through prospective screening, may allow for pre-emptive therapeutic intervention. In this diagnostic area, progress could come from prospective screening strategies using new serodiagnostic assays (galactomannan and (1-3)- $\beta$-D-glucan) and/or polymerase chain reaction (PCR) techniques for the detection of fungal-specific DNA.

Thus, to improve earlier diagnosis and survival of IFIs, new nonculture-based microbiological tools should be used in conjunction with modern imaging techniques in addition to conventional microbiological, histological, and radiological procedures.

\section{Nonculture-based microbiological tools}

With the aim of improving the rapid and early diagnosis of IFIs, new microbiological nonculture-based assays have been developed in the last years, including detection of fungal galactomannan, (1-3)- $\beta$-D-glucan antigen, Candida albicans germ tube antibodies and fungal DNA.

\section{Galactomannan detection}

Galactomannan (GM) is a polysaccharide cell wall component released by the Aspergillus species during hyphal growth. The detection of galactomannan by sandwich-enzyme immunoassay (EIA), Platelia Aspergillus 
(Bio-Rad Laboratories, Marnes-La-Coquette, France), has been approved in Europe and the USA for use in hematopoietic stem cell transplant (HSCT) recipients. Furthermore, its detection in body fluids (mainly serum and bronchoalveolar lavage) was included in the 2002 EORTC-MSG consensus definitions of invasive aspergillosis (IA) as a microbiological criterion having the same weight as the isolation of Aspergillus spp. or the microscopic demonstration of hyphae from a nonsterile body site (Ascioglu et al 2002).

Using EIA, circulating galactomannan may be detected at a median of 5-8 days (range 1-27 days) before clinical signs and symptoms of IA become evident. Furthermore, the concentration of circulating galactomannan corresponds with the fungal tissue burden and may therefore be used to monitor the patient's response to antifungal treatment (Maertens et al 2001).

The results of the unique meta-analysis published of the diagnostic value of GM detection with the Platelia Aspergillus ${ }^{\circledR}$ assay have shown that for proven and probable cases of IA, the pooled (adults and pediatrics) sensitivity was only $61 \%$ whereas the overall specificity was $93 \%$. In general, the negative predictive value and the specificity are excellent (>95\%), suggesting that the assay can be used to rule out the diagnosis of IA (Pfeiffer et al 2006). False-positive results have been reported in adults $(5.7 \%-14 \%)$, but among pediatric patients and neonates these are notably higher (83\%) (Sulahian et al 2003). Reasons for false reactivity remain largely unknown, although piperacillin - tazobactam could be a cause of cross-reactivity in adults (Sulahian et al 2003), and cross-reacting epitopes from Bifidobacterium spp. were proposed as a cause in neonates (Mennink-Kersten et al 2004). In summary, the GM assay has moderate accuracy for the diagnosis of IA in immunocompromised patients. The test is more useful in patients who have hematological malignancies or who have undergone hematopoietic cell transplantation than in solid-organ transplant recipients. Nevertheless, some important issues in relation to the performance of this assay still remain unanswered, such as the impact of antifungal prophylaxis, the influence of therapy with fungal cell wall inhibitors, or the handling of false-positive and false-negative values (Maertens et al 2006).

Recenty, a very interesting study has evaluated GM detection in BAL fluid in critically ill patients with signs of pneumonia. Patients were classified as having proven, probable, or possible IA. Using a cutoff index of 0.5 , the sensitivity and specificity of GM detection in BAL fluid was $88 \%$ and $87 \%$, respectively. The sensitivity of serum
GM was only $42 \%$. In 11 of 26 proven cases of IA, BAL culture and serum GM remained negative, whereas GM in BAL was positive. Following these rresults GM detection in BAL fluid could be useful in establishing or excluding the diagnosis of IA in intensive care units (ICU) (Meersseman et al 2008).

\section{Detection of (I,3)- $\boldsymbol{\beta}$-D-glucan}

Glucans are a cell wall component of most pathogenic fungi except Zygomycetes and Cryptococcus spp. (1-3)- $\beta$-D-glucan can be detected in serum in amounts as low as $1 \mathrm{pg} / \mathrm{ml}$ by commercial assays. One of them, Fungitell (Associates of Cape Cod Inc., East Falmout, MA), has been approved by the FDA as an adjunct for the diagnosis of IFIs in the USA, based on its evaluation in hematological patients (Odabasi et al 2004). At a cut-off of $60 \mathrm{pg} / \mathrm{ml}$, the negative predictive value of twice-weekly sampling was $100 \%$, and sensitivity was $100 \%$ if one positive assay was considered a positive result. Furthermore, the results were not influenced by the use of prophylactic or empirical antifungals. (1,3)- $\beta$-D-glucan is a broad spectrum fungal marker and can detect invasive infections due to Aspergillus, Candida, Fusarium, Acremonium, Scedosporium, Pneumocystis jiroveci, etc., but, after a positive result, the invasive infection must be assessed using radiological and microbiological techniques. To date, overall experience with this test remains limited; furthermore, its methodological concerns (use of endotoxin-free and glucanfree glassware) and false-positive results (due to albumin, immunoglobulins, glucan-containing gauze, hemodialysis or Gram-positive bacteremia) make its use difficult in a clinical setting. However, based on the excellent negative predictive value, detection of (1-3)- $\beta$-D-glucan seems to be most useful for excluding IFIs (Pickering et al 2005).

Multicenter clinical trial results have demonstrated that $(1,3)$ - $\beta$-D-glucan assay can be used in clinical specimens with a high specificity and positive predictive value for subjects with proven or probable IFI when compared with control subjects (Ostrosky-Zeichner et al 2005). This test appears to be useful both as a single-point assay for hospitalized patients with a possible fungal infection and as part of a surveillance strategy in high-risk patients. A cut-off value of 60 or $80 \mathrm{pg} / \mathrm{mL}$ appears to be optimal for this test. At a cutoff of $60 \mathrm{pg} / \mathrm{mL}$, the sensitivity and specificity of the assay were $69.9 \%$ and $87.1 \%$, respectively, with a positive predictive value (PPV) of $83.8 \%$ and a negative predictive value (NPV) of $75.1 \%$. At a cutoff value of $80 \mathrm{pg} / \mathrm{mL}$, the sensitivity and specificity were $64.4 \%$ and $92.4 \%$, respectively, with a PPV of $89 \%$ and an NPV of $73 \%$. 


\section{Detection of fungal DNA}

In recent years novel molecular methods, notably the amplification of gene sequences unique to fungi by polymerase chain reaction (PCR) assays, have been developed to improve the diagnosis of life-threatening IFIs in high-risk patients. PCR offers the potential for rapid diagnosis. However, due to the absence of a standardized and validated commercial method, the routine use of PCR in the diagnosis of IFI cannot yet be recommended. Real-time techniques combined with automated DNA extraction may, however, allow standardization and reproducibility between centers, and may broaden the clinical applicability of PCR-based diagnosis in the near future (Maertens et al 2006).

\section{Antibodies against Candida albicans germ tubes}

A C. albicans mannoprotein located on the germ tube cell wall surface is recognized by sera from patients with invasive candidiasis (IC). Recently, an indirect immunofluorescence assay to detect antibodies (CAGTA) against this antigen has been developed and commercialized (C. albicans IFA IgG; Vircell Laboratories, Spain) (Moragues et al 2004; Ponton et al 1994). The test has shown an overall sensitivity of $77 \%-89 \%$ and a specificity of $91 \%-100 \%$ and has been useful in the diagnosis of IC in intravenous heroin users, bone marrow transplant recipients and hematological or intensive care patients (Quindos et al 2004). Detection of CAGTA in patients with invasive infections caused by Candida spp. other than C. albicans (C. tropicalis, C. parapsilosis, C. glabrata, C. dubliniensis, C. guilliermondii, and C. krusei) may also be positive, although titers are lower than for candidiasis caused by $C$. albicans. In addition, the detection of CAGTA may be useful for the therapeutic monitoring of patients with IC, since the administration of antifungal therapy usually results in decreasing titers of CAGTA (Moragues et al 2004).

In 2006, our group evaluated an immunofluorescence assay for CAGTA detection in a selected population of critically ill patients (Zaragoza et al 2006). Although there were no differences between CAGTA-positive and -negative patients in terms of age, gender, sequential organ failure assessment score, and renal and hepatic failure, the intra-ICU mortality rate was significantly lower in patients who tested positive for CAGTA ( $25 \%$ vs $65.2 \% ; P=0.025)$. These results imply that a strategy based on the early determination of CAGTA expression might reduce the ICU mortality rate of patients with risk factors for the development of IC. However, more studies are needed to validate this approach in the critical care setting.

\section{Combinations of nonculture-based microbiological tools}

Recent studies focusing on the combination of nonculture-based microbiological tools have demonstrated improved diagnostic accuracy when combining galactomannan and (1-3)- $\beta$-D-glucan detection (Pazos et al 2005), as well as galactomannan and PCR (Millon et al 2005; Florent et al 2006). Additionally, its usefulness for diagnosing and monitoring IC using (1-3)- $\beta$-D-glucan and CAGTA was evaluated in neutropenic adults at high risk. Both tests anticipated the clinical and radiological diagnosis, and the initiation of antifungal therapy in most patients. A combination of both tests improved specificity and positive predictive value to $100 \%$ (Pazos et al 2006). These studies suggest that a combination of two tests to detect antigen, antibodies, (1-3)- $\beta$-D-glucan and DNA will be needed to optimize the diagnosis of systemic fungal infections (Ponton and del Palacio 2007).

\section{Culture-based microbiological tools}

Diverse risk factors for IC, including prior Candida spp. colonization, could allow the detection of patients that may be potential candidates for preemptive antifungal therapy. Numerous patients are colonized in the ICU but only few subsequently develop systemic candidiasis. Screening for Candida colonization assessment is performed routinely in many ICUs. Nevertheless, the value of positive surveillance cultures and of several developed colonization indexes for the prediction of IC and the indication for preemptive antifungal therapy is currently under active investigation (Piarroux et al 2004). Recently, a simple scoring system ("Candida score") has been evaluated to assist clinicians in differentiating between Candida species colonization and proven Candida infection in nonneutropenic critically ill patients (Leon et al 2006).

In conclusion, although substantial progress has been made in the diagnosis of IFIs, no single test has found widespread clinical use. There is a consensus in publications that results obtained from a panel of diagnostic tests in association with blood culture findings and clinical aspects of the patient will likely be the most useful strategy for the early diagnosis of patients with IFIs and the monitoring of therapeutic response.

\section{The laboratory and the empirical antifungal therapy}

In patients at high risk of fungal infection, the administration of empirical antifungal treatment must be considered 
since a relationship between the delay in the initiation of treatment and in clinical outcome and hospital mortality has been demonstrated (Morrell et al 2005; Garey et al 2006). Empirical antifungal therapy is defined as the treatment administered to patients who have several risk factors and clinical features for IFIs, when microbiological documentation, species identification or susceptibility data are still not available.

When this treatment is to be established, several factors must be taken into account, such as: 1) the hospital area epidemiology; 2) previous susceptibility data of species isolated in the hospital area; 3 ) the multicenter surveillance studies to predict the susceptibility patterns of isolates; 4) the potential risk of emergence of fluconazole resistance or appearance of candidiasis due to fluconazole-resistant species among patients receiving fluconazole prophylaxis (Agresti et al 1994); 5) the presence of neutropenia; 6) the underlying patient conditions which can affect the metabolism of the drug; 7) the toxicity of the antifungal agent; and 8) previous experience in fungal treatment. Furthermore, it must be kept in mind that any individual isolate of any species may become resistant to any antifungal agent.
Table 1 summarizes the in vitro susceptibility patterns of yeasts and moulds against the most frequently isolated species. These data are representative of those published in numerous in vitro studies.

In summary, as epidemiological data and resistance to antifungal agents depends on characteristics of patients and geographical localization, it is convenient, in all invasive mycoses, to perform both the identification of all isolates at species level and the antifungal susceptibility tests to identify the local epidemiology so as to apply the most appropriate empirical therapy in each institution.

\section{Prophylaxis, empirical, pre-emptive or targeted therapy, which is the best in critically ill patients?}

Approximately $10.4 \%$ of infections in an ICU are related to Candida spp. with the majority being nosocomial (Alberti et al 2002). However, this rate could be underestimated due to the fact that at least $4 \%$ of critically ill patients who die in an ICU present an unexpected fungal infection during postmortem examination (Dimopoulos et al 2004). Furthermore, ICU admission itself has become an independent risk factor

Table I Usual susceptibility patterns for yeasts and moulds

\begin{tabular}{|c|c|c|c|c|c|c|}
\hline Species & Amphotericin B & Fluconazole & Itraconazole & Voriconazole & Posaconazole & Echinocandins \\
\hline C. albicans & $\mathrm{S}^{\mathrm{a}}$ & $S$ & $S$ & $S$ & $S$ & $S$ \\
\hline C. tropicalis & $S$ & S & $S$ & $S$ & $S$ & $S$ \\
\hline C. parapsilosis & $S$ & $S$ & $S$ & $S$ & $S$ & $S^{b}$ \\
\hline C. glabrata & $S, R$ & $S D D, R^{c}$ & $S D D, R^{d}$ & $\mathrm{~S}^{\mathrm{b}}$ & $\mathrm{S}^{\mathrm{b}}$ & $S$ \\
\hline C. krusei & $S, R$ & $\mathrm{R}$ & $S D D, R^{d}$ & $\mathrm{~S}^{\mathrm{b}}$ & $S^{b}$ & $S$ \\
\hline C. lusitaniae & $S, R^{e}$ & S & $S$ & $S$ & $S$ & $S$ \\
\hline C. guilliermondii & $S, R$ & S, SDD & $S$ & $S$ & & $S$ \\
\hline C. dubliniensis & $S, R^{b}$ & $\mathrm{~S}, \mathrm{SDD}, \mathrm{R}$ & $S$ & $S$ & & $S$ \\
\hline Trichosporon spp. & $S, R$ & $\mathrm{~S}, \mathrm{SDD}, \mathrm{R}$ & S, SDD & S & & $\mathrm{R}$ \\
\hline Blastoschizomyces & $S, R$ & S, SDD, R & S, SDD & $S$ & & $\mathrm{R}$ \\
\hline Malassezia spp. & $S, R$ & $S$ & $S$ & $S$ & & ND \\
\hline Rhodotorula spp. & $S$ & S, SDD & S, SDD & S, SDD & & $\mathrm{R}$ \\
\hline Cryptococcus spp. & $S$ & S, SDD & $S$ & S & S & $\mathrm{R}$ \\
\hline A. fumigatus & $S$ & $\mathrm{R}$ & $S, R$ & $S$ & $S$ & $S$ \\
\hline A. terreus & $\mathrm{R}$ & $\mathrm{R}$ & $S$ & S & S & S \\
\hline A. niger & $S$ & $\mathrm{R}$ & $S$ & $S$ & $S$ & $S$ \\
\hline A. flavus & $S$ & $\mathrm{R}$ & $S$ & S & S & $S$ \\
\hline Fusarium solani & $\mathrm{R}$ & $\mathrm{R}$ & $\mathrm{R}$ & S & S & $\mathrm{R}$ \\
\hline S. apiospermum & $\mathrm{R}$ & $\mathrm{R}$ & $\mathrm{R}$ & $S$ & $S$ & S \\
\hline S. prolificans & $\mathrm{R}$ & $\mathrm{R}$ & $\mathrm{R}$ & $\mathrm{R}$ & $\mathrm{R}$ & $\mathrm{R}$ \\
\hline Zygomycetes & $S$ & $\mathrm{R}$ & $\mathrm{R}$ & $\mathrm{R}$ & $S$ & $\mathrm{R}$ \\
\hline
\end{tabular}

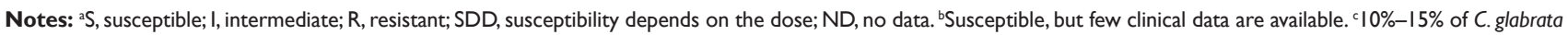
isolates are resistant to fluconazole. ${ }^{d}$ Resistant to itraconazole $\sim 50 \%$ and $\sim 30 \%$ of $C$. glabrata and $C$. krusei isolates, respectively. ${ }^{e} 20 \%$ of isolates are resistant to amphotericin $B$. 
for the development of a Candida spp. infection (Puzniak et al 2004; Tortorano et al 2004).

Candida infections are associated with a significant mortality rate, particularly among critically ill patients (Leleu et al 2002). The crude mortality rate of these infections has been estimated at 40\%-75\%, and the mortality rate attributable to candidemia at 25\%-38\% (Nolla-Salas et al 1997; Petri et al 1997; Tortorano et al 2004; Almirante et al 2005). A review of matched cohort and case-control studies has examined the mortality rate that could be linked to candidemia (Falagas et al 2006). The data suggested that candidemia is indeed associated with a considerable mortality rate that can be attributed to the infection itself.

In recent years, the species of Candida that result in candidemia have shifted from $C$. albicans to non- $C$. albicans (NCA). Approximately half of the reported cases of candidemia are now caused by NCA species (Pfaller et al 2000; Tortorano et al 2004; Almirante et al 2005), and several publications have indicated that these cases have a worse prognosis than those caused by C. albicans (Ben Abraham et al 2004; Klingspor et al 2004; Morgan et al 2005; Dimopoulos et al 2008). This increase has been attributed to the use of fluconazole prophylaxis (Sendid et al 2006). Other adverse outcome predictors described in candidemia episodes are the length of ICU stay, renal failure, thrombocytopenia, hematologic malignancy, and the need for mechanical ventilation or inotropic support (Ben Abraham et al 2004; Almirante et al 2005). In a Spanish multicenter study involving ICU patients in 28 hospitals, an Acute Physiology and Chronic Health Evaluation (APACHE) II score of $>20$ at the time of candidemia was associated with a higher mortality rate (NollaSalas et al 1997), whereas early treatment with antifungal medication and the removal of central venous catheters were protective against death (Nolla-Salas et al 1997; Almirante et al 2005). Furthermore, inadequate empiric antibiotic treatment it is associated with IFIs and a worse prognosis (Parkins et al 2007). Two reports have demonstrated a strong association between a delay in the start of antifungal therapy and an increase in hospital mortality rates (Morrell et al 2005; Garey et al 2006); thus, it is necessary to recognize that time is of the utmost importance when considering the therapy of patients who are at risk for IFIs.

\section{Prophylaxis of Candida infections in ICU}

The implementation of targeted antifungal prophylaxis has been shown to be effective in certain ICU settings (Calandra and Marchetti 2002). Results from controlled randomized trials (Eggimann et al 1999; Pelz et al 2001;
Garbino et al 2002) support the efficacy of azole prophylaxis in nonneutropenic high-risk ICU patients, diminishing the incidence of Candida infection but not mortality.

Three recently published meta-analysis have tried to evaluate the impact of fluconazole prophylaxis on the incidence of fungal infections and on mortality among critically ill surgical patients (Cruciani et al 2005; Shorr et al 2005; Playford et al 2006). The meta-analysis by Shorr and colleagues (2005) demonstrated that prophylactic fluconazole administration in surgical ICU patients appears to successfully decrease the rate of mycoses, but this strategy does not improve survival. The second meta-analysis by Cruciani and colleagues (2005) showed that patients who received azole prophylaxis (fluconazole and ketoconazole) experienced a $80 \%$ relative risk reduction in candidemia, $31.5 \%$ relative risk reduction in overall mortality, and $79.4 \%$ reduction in mortality attributable to Candida infections. Finally, Playford and colleagues (2006) reported reduction of the IFI incidence rate by about $50 \%$ and overall mortality by about $25 \%$.

Currently, because of the potential for both resistance and emergence of non-albicans isolates, clinicians must properly consider these issues when evaluating fluconazole prophylaxis in ICU, although the meta-analyses published by Playford and colleagues (2006) describes above showed no evidence of epidemiological shifts after fluconazole prophylaxis.

In addition, it has been criticized that all controlled randomized trials included into the metaanalyses by Playford and Cruciani and colleagues were limited by their monocentric design and each of them focused on a group of clinically distinctive patients.

Under these circumstances, prophylactic use of fluconazole in high risk ICU patients cannot be generally recommended, but should be restricted to patients with multiple risk factors for developing IC, for instance as Playford recommend, if the cumulative incidence of IC in a certain subpopulation of the ICU approaches or exceeds $10 \%$, in spite of active prevention, prophylaxis should be initiated. Using this approach, the number needed to treat to prevent one case of IC ranges between 17 (for a risk of $11 \%$ ) and nine patients (for a risk of $20 \%$ ). The subgroups of patients who might most benefit from prophylaxis in ICU may be patients with upper gastrointestinal perforation (Pelz et al 2001; Garbino et al 2002), patients with heavy Candida colonization (Piarroux et al 2004), and patients with severe acute pancreatitis (De Waele et al 2003). 


\section{Empirical antifungal treatment in ICU Assessing risk}

The early identification of risk factors for the development of candidemia such as peritonitis, abdominal surgery, previous administration of broad-spectrum antibiotics, parenteral nutrition, multiple lumen catheters, prior Candida spp. colonization, renal replacement therapy, and mechanical ventilation (Petri et al 1997; Blumberg et al 2001; Alvarez-Lerma et al 2003), has become the cornerstone of empiric treatment of fungal infections in the ICU setting in order to reduce the high mortality rate associated with these infections (Ibanez-Nolla et al 2004; Garnacho-Montero et al 2005).

\section{The Ostrosky-Zeichner prediction rule}

In a multicenter retrospective setting, Ostrosky-Zeichner and colleagues (2007) created a prediction rule for IC. The rule was obtained through analysis of a group of 2890 patients, in which incidence of IC was 3\% (88 cases). Statistical modeling revealed a particularly high risk for patients under systemic antibiotic treatment (days 1-3) or with indwelling central venous catheter (days 1-3) and at least two of the following factors: total parenteral nutrition (days 1-3), any dialysis (days 1-3), any major surgery (days $-7-0$ ), pancreatitis (days $-7-0$ ), any use of steroids (days $-7-3$ ), or use of other immunosuppressive agents (days $-7-0$ ). The rule was associated with a sensitivity of $34 \%$, a specificity of $90 \%$, and a PPV and a NPV of $1 \%$ and $97 \%$, respectively. This rule applies to approximately $10 \%$ of patients who stay in the unit for $>4$ days, and approximately $10 \%$ of patients to whom this rule is applied will develop proven or probable IC. In this study, patients with any combination of diabetes mellitus, new-onset hemodialysis, use of total parenteral nutrition, or receipt of broad-spectrum antibiotics had an IC rate of $16.6 \%$. This compared with a rate of $5.1 \%$ in patients who lacked these characteristics $(P=0.001)$. Fifty-two percent of patients who stayed in the ICU for $\geq 4$ days met this rule, and the rule captured $78 \%$ of patients who eventually developed IC.

\section{The Candida score}

A Spanish group reported on the development of a bedside scoring system that allows early antifungal treatment when candidemia is suspected in nonneutropenic ICU patients (Leon et al 2006). This "Candida score" is based on the predictive value of previously reported risk factors. Using a logistic regression analysis and adjusting for possible confounding variables, the authors found several factors to be independently associated with a greater risk for proven candidal infection. The scores for the individual factors were: parenteral nutrition $(+0.908)$, prior surgery $(+0.997)$, multifocal Candida colonization $(+1.112)$, and severe sepsis (+2.038). The authors concluded that a "Candida score" of $>2.5$ could accurately select patients who would benefit from early antifungal treatment (sensitivity $81 \%$, specificity $74 \%$ ).

\section{Pre-emptive antifungal treatment in the ICU}

Poor outcomes are, in part, associated with difficulties in establishing the microbiologic diagnosis at an early stage of infection. Blood culture results are positive in only $50 \%$ of invasive Candida and Fusarium infections, and are very rarely positive in cases of IA. Cultures of bronchoalveolar lavage fluid or brushing specimens are positive in $<50 \%$ of subjects with invasive pulmonary aspergillosis. Finally, positive cultures of specimens from nonsterile body sites may be related to either colonization or infection, and distinguishing between these can be difficult. Nonculturebased diagnostic tests may provide a useful adjunct to these more traditional approaches.

\section{Corrected colonization index}

Piarroux and colleagues (2004) assessed the efficacy of a pre-emptive antifungal therapy in preventing proven candidiasis in critically ill surgical patients, using a corrected colonization index (CCI) (ratio of highly positive samples to the total numbers of samples cultured) to measure the intensity of Candida mucosal colonization. Patients with a CCI value of $\geq 0.4$ received early pre-emptive antifungal therapy with fluconazole, and the incidence of ICU-acquired proven candidiasis decreased significantly from 2.2 to $0 \%$. However, it is possible that the overload of samples sent to the microbiology laboratory could limit the widespread use of this approach.

\section{Targeted treatment of invasive candidiasis in the ICU}

The best first-line treatment for candidemia in critically ill patients remains controversial. Clinical studies have shown that amphotericin $\mathrm{B}(\mathrm{AmB})$, fluconazole, echinocandins, and voriconazole have similar efficacy in the treatment of Candida bloodstream infections (Rex et al 1994; Phillips et al 1997; Mora-Duarte et al 2002; Kullberg et al 2005). In accordance with the last IDSA guidelines (Pappas et al 2004), many experts favor initial treatment with $\mathrm{AmB}$ in severely ill or clinically unstable patients; although the recent published 
Swiss guidelines for fungal infections (Fluckiger et al 2006) do not support this statement. However, its renal toxicity could present a serious problem in these individuals, which may often preclude its use as first-line therapy (Bates et al 2001; Blot et al 2002).

While the triazole, fluconazole, may be selected on the basis of its efficacy and safety (Rex et al 1994; Phillips et al 1997), the increasing frequency of patients infected with Candida strains that are resistant to this drug highlight the need for initial treatment with a broader-spectrum agent, at least until the Candida spp. is identified, in order to avoid inadequate antifungal treatment and an associated increased mortality rate (Zaragoza and Peman 2006). Results from the first randomized, prospective, multicenter study in nonneutropenic patients with candidemia who were treated with either voriconazole alone or $\mathrm{AmB}$ deoxycholate followed by fluconazole have demonstrated equivalence of these two regimens with regard to efficacy and mortality rates (Kullberg et al 2005). Response rates were similar in the voriconazole and $\mathrm{AmB} /$ fluconazole arms; however, for C. tropicalis infection, the response rate was significantly higher in the group treated with voriconazole, despite in vitro susceptibility of these strains to AmB. These results can be easily applied to critically ill patients as approximately half of the patients included in the study were admitted to an ICU. The only limitation to the use of intravenous voriconazole in these patients could be the accumulation and toxicity of its excipient (cyclodextrin) in severe renal dysfunction, although there are no data regarding this concern in patients undergoing renal replacement therapy.

Published reports suggest that caspofungin is equivalent in efficacy to standard therapy with $\mathrm{AmB}$ in the treatment of Candida infections (Mora-Duarte et al 2002). Mora-Duarte and colleagues (2002) compared caspofungin to $\mathrm{AmB}$ in the treatment of IC in nonneutropenic $(\mathrm{n}=200)$ and neutropenic patients $(n=24)$. Caspofungin was as efficacious as $\mathrm{AmB}$, with favourable response rates of $73.4 \%$ and $61.7 \%$, respectively. Micafungin has become the second available echinocandin approved for use in the USA and Japan for the treatment of esophageal candidiasis and prophylaxis in subjects with neutropenia (Chandrasekar and Sobel 2006). Recently, two different studies have been published for invasive candidiasis (Kuse et al 2007; Pappas et al 2007). In these studies, micafungin was as effective as liposomal AmB (Kuse et al 2007) or caspofungin (Pappas et al 2007) as first-line treatment of candidemia and IC and caused fewer adverse events than liposomal AmB. Finally, anidulafungin is the only antifungal compound that has been able to demonstrate superiority over fluconazole in IC (Reboli et al 2007), although we must be cautious with the results presented as the study involved was powered a priori for equivalency. However, anidulafungin's efficacy and safety profile could indicate that it should be readily considered as a first-line option for the treatment of IC.

In the last years, some publications have shown a shift toward the use of antifungal drugs other than fluconazole due to the increasing number of non-C. albicans (NCA) isolates (Sendid et al 2006; Zaragoza and Peman 2006). Consequently, the application of an early de-escalation therapy in critically ill patients with fungal infection should be recommended (Zaragoza and Peman 2006). For this reason, voriconazole (due to its broad spectrum and good profile in the ICU setting), caspofungin, anidulafungin and micafungin (particularly in renal dysfunction) could be attractive options in critically ill patients. Finally, the choice of antifungal drug must be based on the individual characteristics of the patient, and particularly focus on the presence of renal or hepatic failure, hemodinamic instability and possible interactions with other drugs. The presence of hemodynamic instability is a mayor factor for choosing empirical therapy. This fact has been considered by the recent guidelines published enhancing a tailored therapy (de-escalation) especially with severe sepsis or septic shock (Pappas et al 2004; Fluckiger et al 2006). All these guidelines heavily recommend, including last ongoing IDSA guidelines, the use of echinocandins in noneutropenic patients with IC when hemodynamic inestability was present. The high rate of clinical success of these agents in candidemia, their low toxicity, their excellent safety profile and their broad spectrum against non-albicans spp. makes this recommendation feasible. A recent publication has corroborated the use of caspofungin in critically ill patients (DiNubile et al 2007).

In conclusion, IFIs, especially in the critical care setting, have become an excellent target for prophylactic, empiric, and pre-emptive therapy interventions. Table 2 summarizes the antifungal therapy strategies in ICU patients.

\section{Prophylaxis, empirical, pre-emptive or targeted therapy, which is the best in hematological patients?}

Hematological patients are prone to IFI since most of them receive myelotoxic chemotherapy and usually have more than one of well-known risk factors for IFI (eg, long-lasting neutropenia, older age, active cancer, corticosteroid therapy, administration of broad spectrum antibiotics, allogeneic HSCT, central venous catheter, organ dysfunction). 
Table 2 Antifungal therapy strategies in ICU patients

\begin{tabular}{|c|c|c|c|}
\hline & Strategy & Antifungal agent & References \\
\hline Prophylaxis & $\begin{array}{l}\text { No generally recommended. Patients with } \\
\text { upper gastrointestinal perforation, heavy } \\
\text { Candida colonization or with severe acute } \\
\text { pancreatitis might be benefited }\end{array}$ & Fluconazole & $\begin{array}{l}\text { Pelz et al } 200 \text { I; Garbino et al } 2002 ; \text { De } \\
\text { Waele et al 2003; Piarroux et al } 2004\end{array}$ \\
\hline Empirical & $\begin{array}{l}\text { Use of "Candida score" or the } \\
\text { Ostrosky-Zeichner prediction rule }\end{array}$ & $\begin{array}{l}\text { De-escalation therapy }(*) \text {, the choice } \\
\text { of antifungal drug must be based on } \\
\text { the individual characteristics of the } \\
\text { patient }\end{array}$ & $\begin{array}{l}\text { Leon et al 2006; Ostrosky-Zeichner } \\
\text { et al } 2007\end{array}$ \\
\hline Pre-emptive & $\begin{array}{l}\text { Based on detection of galactomannan, } \\
(I, 3)-\beta \text {-D-glucan or C. albicans germ tube } \\
\text { antibodies }\end{array}$ & $\begin{array}{l}\text { De-escalation therapy }(*) \text {, the choice } \\
\text { of antifungal drug must be based on } \\
\text { the individual characteristics of the } \\
\text { patient }\end{array}$ & $\begin{array}{l}\text { Ostrosky-Zeichner et al 2005; } \\
\text { Zaragoza et al 2006; Meersseman } \\
\text { et al } 2008\end{array}$ \\
\hline Targeted & Based on sterile site culture results & $\begin{array}{l}\text { De-escalation therapy }(*) \text {, the choice } \\
\text { of antifungal drug must be based on } \\
\text { the individual characteristics of the } \\
\text { patient }(* *)\end{array}$ & $\begin{array}{l}\text { Rex et al I994; Phillips et al I997; } \\
\text { Mora-Duarte et al 2002; Kullberg et al } \\
\text { 2005; Zaragoza and Peman 2006; Kuse } \\
\text { et al 2007; Pappas et al } 2007\end{array}$ \\
\hline
\end{tabular}

Notes: "An early broad-spectrum antifungal agent is initially prescribed, switching to a narrower-spectrum drug (fluconazole) when mycological identification and susceptibility studies are provided. "Focus on the presence of renal or hepatic failure, hemodynamic instability and possible interactions with other drugs.

These patients are usually polymedicated and are thus exposed to harmful drug interactions. Furthermore, it is important to emphasize that the same individual patient will be at risk at several time points through the entire treatment plan for his/her underlying disease. Thus, the planned antineoplastic treatment should be kept in mind when designing antifungal strategies for hematological patients.

\section{Prophylaxis of IFI in hematological patients}

Historically, outcomes for IFI have been disappointing and associated with a high mortality rate. Because of this, prophylaxis has been the first option to consider in hematological patients. Since the early 90 's, fluconazole prophylaxis has reduced infections caused by Candida spp. but dramatic changes in the epidemiology of IFI have occurred, with Aspergillus spp. and NCA species becoming increasingly common. These changes have affected the selection of antifungals for first-line or prophylactic use, as not all agents have the spectrum of activity required. At this point, it should be noted that evidence based recommendations are to be interpreted with caution and so we should always consider the moment when they were formulated. For example, benefit of antifungal prophylaxis with fluconazole (400 mg/day) in allogeneic HSCT recipients continues to be an A-I recommendation but today C. albicans is not longer the predominant pathogen in this setting. However, newer azoles have the potential to provide protection against mould infections that are difficult to treat once they occur. Two large randomized, fluconazole- or itraconazole-based controlled clinical trials in acute leukemia patients (Cornely et al 2007b) and in HSCT recipients with graft-versus-host disease (GVHD) (Ullmann et al 2007) have demonstrated the efficacy of oral posaconazole (200 $\mathrm{mg}$ thrice daily) for reducing invasive mould infections. Ideally prophylaxis should usually be initiated in parallel with the administration of cytotoxic therapy in order to ensure a protective effect at the time of maximal neutropenia and intestinal epithelial damage, but concerns over drug interactions make advisable to start triazole-based prophylaxis after the administration of cytotoxic therapy, especially in HSCT recipients. The ability to switch from the oral to an intravenous formulation for the same antifungal product in the setting of severe oral mucositis is an advantage. Both oral solution and intravenous formulation of itraconazole are suitable for prophylaxis in high-risk patients, but compliance with the oral solution is poor (Marr et al 2004b). A preliminary report of a large trial to assess prophylactic voriconazole in allogeneic HSCT recipients (oral or IV $200 \mathrm{mg}$ BID) was recently presented (Wingard et al 2007). Prophylaxis with micafungin (van Burik et al 2004) and caspofungin (Mattiuzzi et al 2006) have been studied at daily IV doses of $50 \mathrm{mg}$ but echinocandins are preferred in the clinical practice for therapy instead of prophylaxis. The end of prophylaxis should be dictated by the termination of the specific risk. Mould-active prophylaxis may require administration into the late post-engraftment period in allogeneic HSCT for those patients with higher 
risk due to acute or chronic GVHD requiring augmented immunosuppressive therapy (Marr et al 2004b; Ullmann et al 2007). Finally, the use of aerosolized lipid-based formulations of AmB may prove to be useful as prophylaxis for mould infection in the respiratory tract, the major portal of entry of fungal conidia (Rijnders et al 2008). The combination of nebulized AmB with fluconazole is an interesting approach to avoid drug interactions (eg, in patients receiving vinca alkaloids).

\section{Empirical therapy of IFI in hematological patients}

For lower risk patients or when IFI is suspected in patients receiving prophylaxis, empirical antifungal therapy is often employed following a predefined duration of fever. During the early 1980s one quarter to one third of severely neutropenic cancer patients with persistent or relapsing fever despite broad-spectrum antibacterial therapy developed IFI. Empirical AmB deoxycholate reduced the incidence of IFI and overall mortality by $50 \%-80 \%$ and $23 \%-45 \%$, respectively. Fever is a poorly predictive surrogate upon which to base an intervention such as empirical antifungal therapy (De Pauw 2005). Although a substantial number of leukemia patients and HSCT recipients are given empirical antifungal therapy, proven IFI occurs in only $2 \%$ to $15 \%$ (Kanda et al 2000 ; Bow et al 2002; Ullmann et al 2002; Cornely et al 2007b) suggesting that the current guidelines (Hughes et al 2002) based upon persistent neutropenic fever are significantly flawed and may result in unjustifiable excess treatment-related toxicities and resource expenses (De Pauw 2005).

Currently, caspofungin and liposomal AmB are the first-line option for treating patients with febrile neutropenia (Walsh et al 1999, 2004). The role of voriconazole as an empirical treatment for patients with febrile neutropenia remains unresolved, and in fact, voriconazole is currently not licensed for this indication. The results of a large, international, multicenter, randomized study that compared voriconazole with liposomal $\mathrm{AmB}$ for the empirical treatment of febrile neutropenic patients have been controversial (Walsh et al 2002). According to the predefined end point of this study (noninferiority), voriconazole did not achieve this goal relative to liposomal AmB; the overall success rates were $26 \%$ and $30.6 \%$, respectively. Breakthrough fungal infections occurred in eight patients $(1.9 \%)$ in the voriconazole group compared with 21 patients $(5 \%)$ in the liposomal AmB group $(P=0.02)$. However, more patients died in the voriconazole group and a claimed significant reduction in the number of breakthrough fungal infections disappeared when patients arbitrarily excluded from analysis by the trial authors were included (Jorgensen et al 2006).

Continuous infusion administration $\mathrm{AmB}$ has been proposed over the past few years, claiming it could reduce the risk of nephrotoxicity associated to this agent. The preliminary results of an open study, including 80 neutropenic patients during 4 hour infusion versus continuous infusion, suggest more advantages for continuous infusion. A significantly lower incidence in reactions related with the infusion was found in the case of continous administration, which also favored the creatinine clearance values (Eriksson et al 2001). Another cohort study on 81 febrile neutropenic hematological patients with a higher IFI risk, evaluated the administration of $\mathrm{AmB}$ in intermittent infusion during 4h, compared to a continuous infusion (Peleg and Woods 2004). Kidney failure was seen in $45 \%$ and $10 \%$ of the patients, respectively (OR 0.14; IC 95\% 0.04-0.5; $P<0.001$ ). The result was similar in patients with allogeneic transplant and in those which were given other nephrotoxic drugs. A multivariate logistic regression showed that the continuous infusion was the only variable significantly associated to kidney failure, with a protective effect.

Nevertheless, the use of continuous infusion is still controversial. Whilst some authors defend this strategy before opting for lipid or liposomic formulations (Johnson 2004; Schneemann and Bachli 2004), others do not consider it totally acceptable because of limited experience. Altmannsberger and colleagues (2007), when repeating the experience provided by Peleg and Woods (2004), found no significant advantages between intermittent and continuous infusion in patients with a high IFI risk.

\section{Pre-emptive therapy of IFI in hematological patients}

A more refined approach is pre-emptive therapy where treatment is only initiated upon positive identification of a surrogate marker of infection in combination with clinical and radiological signs. This pre-emptive therapy will subject fewer patients to toxic and expensive treatments. The interest in this strategy is based upon the observation that early detection is associated with better outcomes. A study in acute leukemia patients receiving fluconazole prophylaxis examined an algorithm-based pre-emptive approach based upon serial diagnostic testing and clinical monitoring (Maertens et al 2005). Only patients with $\geq 2$ positive serum GM assays or CT and or bronchoscopic evidence for mould infection received antifungal therapy. A total of 41 of 117 febrile neutropenic episodes (35\%) had persistent neutropenic 
fever; however, only 9 patients $(22 \%$ of the 41 persistent neutropenic fevers; $8 \%$ of the original febrile neutropenic episodes) satisfied the pre-defined criteria for antifungal therapy. Despite these promising observations, the appearance of a clinical or radiological marker such as a suggestive nodular pulmonary infiltrate on computerized thoracic tomography in a high-risk patient will compel the anxious physician to initiate antimould therapy independent of molecular markers. Pre-emptive strategies are intellectually attractive because they combine in an elegant manner newer diagnostic tools in order to give antifungal therapy only to patients who really deserve it. However, in the real world, they are difficult to carry out. Furthermore, nonculture methods such is serum GM assay lose diagnostic power if an anti-mould prophylaxis is given, which in turn will be given to higher risk patients. Thus pre-emptive therapy based on sensitive diagnostic non-culture methods needs further validation in larger randomized trials before becoming a standard.

\section{Targeted therapy of IFI in hematological patients}

Targeted therapy is used in patients with confirmed IFI. Again hematological patients deserve especial consideration as they are commonly at high risk of hemorrhagic complications that render them unfit for aggressive diagnostic procedures including biopsies. Therefore many suspected cases will be diagnosed as probable IFI at the most.

A study comparing voriconazole to conventional AmB in 277 patients (Herbrecht et al 2002) demonstrated higher response rates among voriconazole recipients (52.8\% versus $31.6 \%$ ), a $67 \%$ improvement. Patients with early lesions characterized by pulmonary nodules with halos had higher treatment response rates (52.4\% versus $29.1 \%$ ) (Greene 2005). Moreover, a survival advantage for voriconazole recipients was observed $(70.8 \%$ compared to $57.9 \%$, $P=0.024)$. Despite this, response among allogeneic HSCT recipients remained suboptimal (32.4\% for voriconazole versus $13.3 \%$ for conventional $\mathrm{AmB}$ ). A study of dose-intense ( $10 \mathrm{mg} / \mathrm{kg} / \mathrm{d}$ for 14 days followed by $3 \mathrm{mg} / \mathrm{kg} / \mathrm{d}$ vs $3 \mathrm{mg} / \mathrm{kg} / \mathrm{d}$ ) of liposomal AmB as primary therapy for IA demonstrated similar response rates ( $46 \%$ vs 50\%, respectively), but more nephrotoxicity (31\% versus 14\%), hypokalemia (30\% versus $16 \%)$, and higher mortality in the dose-intense group (41\% versus 28\%) (Cornely et al 2007a). Based on this experience, the value of dose-intensity for IA appears limited.

Poor response rates for primary and salvage monotherapy therapy for IFI and the availability of increasingly safer agents with differing mechanisms of action have prompted hematologists to use early combination therapy. Arguments for considering combination therapy include enhanced fungal killing (synergy), an enhanced spectrum of activity, prevention of development of resistance, and reduction of drug-related toxicities (Kontoyiannis and Lewis 2004). Favorable responses were observed among HSCT patients failing polyene-based therapy for IA with a combination of voriconazole and caspofungin compared to voriconazole monotherapy (Marr et al 2004a). Recently, a French multicenter randomized study comparing combination therapy with liposomal AmB (3 mg/kg/d) plus caspofungin (70 mg day 1 and $50 \mathrm{mg} / \mathrm{d}$ thereafter) versus high-dose liposomal AmB monotherapy $(10 \mathrm{mg} / \mathrm{kg} / \mathrm{d})$ for primary treatment of IA was published (Caillot et al 2007). A favorable overall response was observed in $67 \%$ combination therapy recipients compared to $27 \%$ high-dose therapy recipients $(P=0.028)$. The results of this small pilot, representing the first prospective study of combination therapy in IA, are encouraging but need confirmation. Combination antifungal therapies are expensive and potentially toxic and there are limited well-designed randomized-controlled trials to guide the practicing clinician faced with managing these problems.

In conclusion, risk-adapted prophylaxis is the best option in hematological patients. Table 3 resumes the antifungal therapy strategies in these patients.

\section{Prophylaxis, empirical, pre-emptive or targeted therapy, which is the best in solid organ transplant recipients (SOT)?}

Renal, liver, heart, and lung transplantation are now considered to be the standard therapeutic interventions in patients with end-stage organ failure. The use of newer more potent immunosuppressive regimens as well as widespread use of antifungal drugs has changed the landscape of fungal infections. The incidence of invasive mycoses following SOT ranges from $5 \%$ to $42 \%$ depending on the organ transplanted (Marik 2006; Singh 2004; Solé and Salavert 2007). Fungal infections in SOT recipients continue to be a significant cause of morbidity and mortality. The clinical and epidemiological characteristics of IFIs in recipients of nonpulmonary solid organ transplantation (NP-SOT) are very different from which occurs in the patients with lung transplantation (LT) or HSCT. The incidence of invasive mycoses varies with type of SOT, though Candida spp. and Aspergillus spp. account for most IFI in SOT recipients (Silveira and Husain 2007). 
Table 3 Antifungal therapy strategies in hematological patients

\begin{tabular}{|c|c|c|c|}
\hline & Strategy & Antifungal agent & References \\
\hline \multirow[t]{2}{*}{ Prophylaxis } & High risk patients*: & $\begin{array}{l}\text { Itraconazole or } \\
\text { Posaconazole or } \\
\text { Voriconazole }\end{array}$ & $\begin{array}{l}\text { Jarque et al 2004; Marr et al 2004b; } \\
\text { Cornely et al 2007b; Ullmann et al 2007; } \\
\text { Wingard et al } 2007\end{array}$ \\
\hline & Intermediate risk patients**: & Fluconazole & \\
\hline Empirical & $\begin{array}{l}\text { Severely neutropenic cancer patients } \\
\text { with persistent or relapsing fever despite } \\
\text { broad-spectrum antibacterial therapy }\end{array}$ & $\begin{array}{l}\text { Liposomal AmB or } \\
\text { Caspofungin }\end{array}$ & Hughes et al 2002; Walsh et al 1999, 2004 \\
\hline Pre-emptive & $\begin{array}{l}\text { Based on GM assays or CT } \\
\text { or bronchoscopic cultures }\end{array}$ & $\begin{array}{l}\text { Liposomal AmB or } \\
\text { Caspofungin or } \\
\text { Voriconazole }\end{array}$ & Maertens et al 2005 \\
\hline Targeted & Based on sterile site culture results & $\begin{array}{l}\text { Voriconazole } \\
\text { Combination therapy }\end{array}$ & $\begin{array}{l}\text { Herbrecht et al 2002; Marr et al 2004a; } \\
\text { Caillot et al } 2007\end{array}$ \\
\hline
\end{tabular}

Notes: "Acute leukemia patients,Allogenic HSCT recipients, autologous HSCT recipients, previous episode of IFI, rescue chemotherapy for acute leukemia patients and severe aplastic anemia. ${ }^{* * *}$ Autologous HSCT recipients, acute linfoblastic leukemia, rescue therapy for myeloma and lymphomas.

Liver transplant recipients have highest reported incidence of Candida infections while LT recipients have highest rate of Aspergillus infections (Singh 2005; Singh and Paterson 2005; Solé et al 2005; Solé and Salavert 2008). Recent epidemiological studies suggest the emergence of resistant strains of Candida as well as mycelial fungi other than Aspergillus in these patients. Moreover, significant percentages of fungal infections are occurring late in the course of transplantation. SOT recipients also are at risk for Cryptococcus infections (Singh et al 2007) and reactivation of endemic mycoses such as histoplasmosis and coccidiomycosis.. Emergence of newer and more potent antifungal agents with lower toxicity potentially changes the concept of antifungal prophylaxis (van Burik 2005; Metcalf and Dockrell 2007).

\section{Prophylaxis and pre-emptive therapy of IFI in solid organ transplant patients}

Several prophylactic strategies with antifungal drugs have been reported to result in a decreased incidence and mortality of fungal disease in LT recipients (Covarrubias and Milstone 2005; Husain et al 2006b; Magill and Dropulic 2006); however, there has not been a uniform approach, data are limited, and besides there is a considerable variation in antifungal prophylaxis practices among LT centres throughout the world. The majority of LT programs are using universal antifungal prophylaxis in the postoperative period; about $30 \%$ use a pre-emptive approach for patients with pre- and/or post-transplant fungal airway colonization. As the antifungal agent used as the duration of prophylaxis varies substantially from center to center (Husain et al 2006b). It is clear that there is considerable uncertainty to which approach (prophylaxis or pre-emptive therapy) is most appropriate, which agent is the best, and what duration of prophylaxis or pre-emptive therapy is needed. Antifungal prophylaxis in LT recipients should be taken into account the incidence of colonization, anastomoses healing, chronic rejection, and the time of LT, thus providing a rationale for the duration of therapy.

To prevent invasive pulmonary aspergillosis, multiple strategies and antifungal drugs have been utilized such as oral itraconazole, voriconazole or aerosolized AmB used alone or in combination. Aerosolized medication regimens are an attractive option, as drug interactions and systemic toxicities are likely to be limited (Drew 2006). Lipid preparations of AmB appear to be ideal for inhalational administration; however, there are not rigorous pharmacokinetic studies in LT recipients, to determine the appropriate dose and schedule of their administration. Monforte and colleagues have demonstrated that aerosolized $\mathrm{AmB}$ and lipid preparations of $\mathrm{AmB}$ are safe and achieve high concentrations in BAL fluid for the first 24 hours and 14 days, respectively, following nebulization (Monforte et al 2003, 2005). These lipid formulations let a delayed administration (every 7-14 days), which is rebounded and better accomplished by patient. Several centers have reported on the safety of aerosolized AmB with a variety of dosing regimens (Reichenspurner et al 1997; Calvo et al 1999; Monforte et al 2003), and others with 
aerosolized AmB lipid formulations (Palmer et al 2001; Drew et al 2004; Lowry et al 2007). Our group has used aerosolized AmB as part of the post-LT protocol since 1994 (Calvo et al 1999). Since three years ago we also are using AmB lipid complex, with the same respiratory tolerability and safety that aerosolized AmB, but AmB lipid complex results more comfortable for long periods of time (50 mg inhaled/ weekly), and patients have better adherence to treatment. Recently, in vitro suitability of caspofungin for aerosol administration has been characterized (Wong-Beringer et al 2005). Caspofungin solution appeared to have physicochemical and aerodynamic characteristics suitable for aerosolization. However, further in vivo testing is warranted. Although the incidence of IFI seems to be reduced with aerosolized AmB prophylaxis, the efficacy of this approach has not been determined in a large prospective clinical trial. Furthermore, without detectable levels of $\mathrm{AmB}$ in the circulation, extrapulmonary fungal infections may not be prevented by this strategy. Besides, it is important to take into consideration the type of delivery systems used for inhaled drugs (Corcoran et al 2006; Hagerman et al 2006). In addition, contamination of the nebulization systems used in the prophylaxis with AmB nebulized in LT has been described (Monforte et al 2003). The contamination of the nebulizing systems may be the origin of respiratory infections and it is frequent when no strict cleaning and disinfection protocol is followed.

In conclusion, aerosolized antifungal therapy is a promising route of drug delivery for pulmonary aspergillosis due to attainment of high localized concentrations (Mohammad and Klein 2006; Solé and Nieto 2007).

Respect to oral prophylaxis, recently a study that examined the efficacy and toxicity of a strategy of universal de novo antifungal prophylaxis with voriconazole compared to targeted antifungal prophylaxis has been published (Husain et al 2006a). The main finding of this study was that the overall rate of IA at 1 year decreased to $1.5 \%$ with universal voriconazole prophylaxis as compared to $23.5 \%$ with a targeted prophylaxis strategy. Interestingly, the rate of Candida colonization, particularly non-albicans spp. in the voriconazole group was significantly higher. In the voriconazole prophylaxis cohort, $27 \%$ of the LT recipients had normal liver enzymes throughout the course of the study. The main handicap of this azole therapy is the strong interaction with immunosuppressors that obliges to monitoring calcineurin inhibitors to avoid toxicity or rejection. Other interesting finding was that universal voriconazole prophylaxis did not increase the rate of non-Aspergillus fungal infections (specially, zygomycosis).
Available echinocandins (caspofungin, micafungin, anidulafungin) may have an important role in prophylaxis because of their antifungal profile, pharmacokinetics and security; however, they are expensive and need intravenous administration.

Another question is how long should be prophylaxis maintained? The majority of centers agree to apply universal prophylaxis during first period post transplant (3 months) after this time, each center use a tailored prophylaxis. Besides, it is recommended to use nebulized antifungal prophylaxis and/or preemptive therapy with antifungal agents (voriconazole) in patients with chronic rejection and respiratory samples positive for Aspergillus, even without clinical or radiological signs, mainly in single LT patients due to the high risk of IA (Solé et al 2005). This preemptive treatment should last for at least 6 months, the time period over which colonization has been shown to precede disseminated infection (Singh and Husain 2003) and in some cases for life. Table 4 shows antifungal therapy strategies in LT patients.

Due to the difficulty in obtaining a proven diagnosis of IFI, empiric and pre-emptive therapy plays an important role in NP-SOT patients (Table 5) (Leather and Wingard 2006; Bow 2008). As it is mentioned in Table 6, some of NP-SOT recipients have additional risk factors that increases the probability of suffer an IFI caused by Aspergillus spp. (EchanizQuintana et al 2004; Singh 2005; Singh et al 2006b, 2006c). For this reason, the incorporation of a strategy of antifungal prophylaxis adapted-to-risk is accepted and high risk patients need to be identified in order to prevent the development of the disease (Playford et al 2004; Castroagudin et al 2005; Hellinger et al 2005).

Since the IFI risk is lower in the cardiac and kidney recipient patients, we will make reference mainly to patients with orthotopic liver transplantation (OLT) as paradigm of the indication of antifungal prophylaxis in NP-SOT patients. However, prophylaxis of candidiasis in SOT recipients is a challenging topic. Strategies to prevent IC should be based on institutional trends and, when appropriate, should target high-risk patients only (Singh 2000). Only a few well-designed studies have been conducted and all of the controlled trials were performed in liver transplant recipients. Oral prophylaxis with nonabsorbable antifungal agents (nystatin, clotrimazole, AmB) has shown inconsistent results (Wiesner et al 1988; Arnow et al 1996; Hjortrup et al 1997; Hellinger et al 2002). Two randomized controlled trials have shown the efficacy of fluconazole in the prophylaxis of IC. In one study, comparing fluconazole $100 \mathrm{mg} /$ day for the first 4 weeks following liver transplantation to oral 
Table 4 Antifungal therapy strategies in lung transplantation (LT) recipients

\begin{tabular}{|c|c|c|c|}
\hline & Strategy & Antifungal agents & References \\
\hline Prophylaxis & $\begin{array}{l}\text { Generally recommended in the postoperative } \\
\text { period }\end{array}$ & $\begin{array}{l}\text { Voriconazole or } \\
\text { Amphotericin B (intravenous } \\
\text { or aerosolized) }\end{array}$ & $\begin{array}{l}\text { Calvo et al 1999; Monforte et al 2005; } \\
\text { Husain et al 2006a; Drew 2006; } \\
\text { Lowry et al } 2007\end{array}$ \\
\hline Pre-emptive & $\begin{array}{l}\text { Patients with pre- and/or post-transplant } \\
\text { fungal airway colonization } \\
\text { Patients with chronic rejection and } \\
\text { respiratory samples positive for Aspergillus, } \\
\text { mainly in single LT patients } \\
\text { Detection of galactomannan antigen of } \\
\text { Aspergillus, (I,3)- } \beta \text {-D-glucan or C. albicans } \\
\text { germ tube antibodies are not reliable } \\
\text { methods with usefulness sufficiently } \\
\text { demonstrated in the LT }\end{array}$ & $\begin{array}{l}\text { Voriconazole or } \\
\text { Amphotericin B (intravenous } \\
\text { or aerosolized) }\end{array}$ & $\begin{array}{l}\text { Singh and Husain 2003; } \\
\text { Sole et al } 2005\end{array}$ \\
\hline Targeted & $\begin{array}{l}\text { Based on sterile site culture results or } \\
\text { non-absolutely sterile samples (respiratory } \\
\text { specimens) processed by semi or quantitative } \\
\text { methods and considered clinically significant } \\
\text { AND/OR } \\
\text { Based in histological studies of biopsies and } \\
\text { other clinical specimens obtained by instru- } \\
\text { mental or chirurgic procedures (respiratory } \\
\text { and non-respiratory samples) }\end{array}$ & $\begin{array}{l}\text { Voriconazole or } \\
\text { Amphotericin B or } \\
\text { Echinocandins } \\
\text { Combination therapy (triazole plus } \\
\text { echinocandin) in those patients with } \\
\text { LT and renal failure or infected by } \\
\text { A. fumigatus }\end{array}$ & $\begin{array}{l}\text { Herbrecht et al 2002; } \\
\text { Singh et al } 2006 \text { a }\end{array}$ \\
\hline
\end{tabular}

Table 5 Antifungal therapy strategies in recipients of nonpulmonary solid organ transplantation (NP-SOT)

\begin{tabular}{|c|c|c|c|}
\hline & Strategy & Antifungal agents & References \\
\hline Prophylaxis & $\begin{array}{l}\text { Universal prophylaxis is not recommended } \\
\text { Antifungal prophylaxis adapted-to-risk is } \\
\text { reasonable } \\
\text { High-risk NP-SOT recipients need } \\
\text { to be identified in order to prevent } \\
\text { the development of IFI }\end{array}$ & $\begin{array}{l}\text { Oral prophylaxis with nonabsorbable } \\
\text { antifungal agents (nystatin, } \\
\text { clotrimazole, amphotericin B) has } \\
\text { shown inconsistent results. } \\
\text { Azoles (fluconazole, itraconazole) or } \\
\text { Amphotericin B (lipid formulations) } \\
\text { or Echinocandins (caspofungin) }\end{array}$ & $\begin{array}{l}\text { Lumbreras et al I996; Winston } \\
\text { et al 1999; Singh et al 200I; } \\
\text { Winston and Busuttil 2002; Fortun } \\
\text { et al 2003, 2007; Sharpe et al 2003; } \\
\text { Hellinger et al 2002, 2005; Munoz } \\
\text { et al 2004; Castroagudin et al } 2005\end{array}$ \\
\hline Pre-emptive & $\begin{array}{l}\text { Strategy not sufficiently validated in these } \\
\text { patients } \\
\text { Detection of galactomannan antigen of } \\
\text { Aspergillus, }(I, 3) \text { - } \beta \text {-D-glucan or C. albicans germ } \\
\text { tube antibodies are not usefulness in NP-SOT } \\
\text { recipients }\end{array}$ & $\begin{array}{l}\text { Azoles or } \\
\text { Amphotericin B }\end{array}$ & Akamatsu et al 2007; Perkins 2007 \\
\hline Targeted & $\begin{array}{l}\text { Based on sterile site culture results or } \\
\text { nonabsolutely sterile samples (respiratory } \\
\text { specimens) processed by semi or quantitative } \\
\text { methods and considered clinically significant } \\
\text { AND/OR } \\
\text { Based in histological studies of biopsies } \\
\text { and other clinical specimens obtained } \\
\text { by instrumental or chirurgic procedures } \\
\text { (respiratory and non-respiratory samples) }\end{array}$ & $\begin{array}{l}\text { Combination therapy (triazole plus } \\
\text { echinocandin) in patients with SOT } \\
\text { and renal failure or infected by } \\
\text { A. fumigatus }\end{array}$ & Herbrecht 2002; Singh et al $2006 a$ \\
\hline
\end{tabular}


Table 6 Etiological and clinical characteristics of IFI according to the type of SOT

\begin{tabular}{|c|c|c|c|c|}
\hline Type of transplant & Incidence of IFI (\%) & Usual etiologic agent (s) & $\begin{array}{l}\text { Variables portending higher } \\
\text { risk of IA }\end{array}$ & $\begin{array}{l}\text { Mortality } \\
\text { (\%) of IA }\end{array}$ \\
\hline \multirow[t]{2}{*}{ Renal } & $0-20$ & $\begin{array}{l}\text { 76\%-95\% Candida (mainly } \\
\text { urinary tract infections), }\end{array}$ & $\begin{array}{l}\text { Graft failure requiring hemodialysis, } \\
\text { high level and prolonged duration } \\
\text { of corticosteroids }\end{array}$ & 77 \\
\hline & & $0 \%-25 \%$ Aspergillus & & \\
\hline Heart & $5-20$ & $\begin{array}{l}\text { 70\%-90\% Aspergillus, } \\
8 \%-25 \% \text { Candida }\end{array}$ & $\begin{array}{l}\text { Isolation of Aspergillus species } \\
\text { in respiratory tract cultures, } \\
\text { reoperation, post-transplant } \\
\text { hemodialysis, CMV disease }\end{array}$ & 78 \\
\hline Liver & $5-40$ & $\begin{array}{l}35 \%-0 \% \text { Candida, } 9 \%-45 \% \\
\text { Aspergillus }\end{array}$ & $\begin{array}{l}\text { Retransplantation, renal failure } \\
\text { (particularly requiring renal } \\
\text { replacement therapy), fulminant } \\
\text { hepatic failure as an indication } \\
\text { for transplantation, primary } \\
\text { allograft failure, high transfusion } \\
\text { requirements, use of monoclonal } \\
\text { antibodies, }\end{array}$ & 87 \\
\hline Lung/Heart-Lung & $10-45$ & $\begin{array}{l}43 \%-72 \% \text { Candida, } \\
25 \%-50 \% \text { Aspergillus }\end{array}$ & $\begin{array}{l}\text { Single lung transplant, CMV } \\
\text { infection, rejection and augmented } \\
\text { immunosuppression, obliterative } \\
\text { bronchitis, Aspergillus colonization, } \\
\text { acquired hypogammaglobulinemia, } \\
\text { presence of bronchial stents, } \\
\text { reperfusion injury, airway ischemia }\end{array}$ & 68 \\
\hline Pancreas (+kidney) & $10-40$ & $\begin{array}{l}>90 \% \text { Candida, } \\
0 \%-3 \% \text { Aspergillus }\end{array}$ & $\begin{array}{l}\text { Similar factors to the liver } \\
\text { and kidney transplant, } \\
\text { graft lost (vascular graft } \\
\text { thrombosis, post-reperfusion } \\
\text { pancreatitis), enteric drainage, } \\
\text { alemtuzumab-containing } \\
\text { immunosuppresive regimen }\end{array}$ & 100 \\
\hline Small bowel & $30-60$ & $\begin{array}{l}80 \%-100 \% \text { Candida, } 0 \%-5 \% \\
\text { Aspergillus }\end{array}$ & $\begin{array}{l}\text { Not clearly determined, similar } \\
\text { factors to others intraabdominal } \\
\text { SOT recipients; Graft } \\
\text { rejection/dysfunction, enhanced } \\
\text { immunosuppression, anastomotic } \\
\text { disruption, multi-visceral transplant }\end{array}$ & 66 \\
\hline
\end{tabular}

Abbreviations: SOT, solid organ transplantation/solid organ transplant recipients; IFI, invasive fungal infection; IA, invasive aspergillosis; CMV, cytomegalovirus.

nystatin, fluconazole was associated with a reduction in Candida colonization and superficial infections, as well as a trend toward reduction of invasive infections (Lumbreras et al 1996). In a randomized, placebo-controlled study, fluconazole $400 \mathrm{mg} /$ day for 10 weeks after liver transplantation prevented most types of Candida infection, except those caused by $C$. glabrata and C. krusei. In another double blind randomized control trial itraconazole decreased the rate of fungal infection from $24 \%$ to $4 \%$ in liver transplant recipients (Sharpe et al 2003). A recently published meta-analysis showed that antifungal prophylaxis in liver transplant recipients significantly reduced the total episodes of superficial and IFI caused by yeasts (at least for C. albicans), as well as mortality attributable to fungal infections; however, it did not affect overall mortality or the need for empirical antifungal treatment (Cruciani et al 2006). Compared to controls, patients receiving prophylaxis experienced a higher proportion of episodes of Candida non-albicans infections. Prophylactic strategies against invasive Candida infections should be reassessed periodically because risk factors continue to evolve in liver transplant recipients (Husain et al 2003).

Antifungal prophylaxis to prevent IA remains an unsettled issue in NP-SOT. To date, no prospective randomized studies have demonstrated that antifungal prophylaxis 
prevents IA in OLT. A recent meta-analysis of antifungal prophylaxis in OLT demonstrated no beneficial effect on IA. Observational studies, however, suggest that targeted prophylaxis with lipid formulations of AmB may be effective in preventing IA in high-risk OLT recipients (Singh et al 2001; Fortun et al 2003). Lipid formulations of AmB at a dose of $5 \mathrm{mg} / \mathrm{kg} /$ day have been shown to be efficacious in reducing IFI in high-risk OLT recipients on renal replacement therapy, although there was no reduction in mortality. A study of universal prophylaxis with cumulative doses of 1-1.5 $\mathrm{g}$ of liposomal or lipid complex AmB showed a reduction in the incidence of IA, which was most significant among patients receiving renal replacement therapy ( $0 \%$ vs $32 \%$ on controls). However, low doses of lipid formulations of AmB failed to prevent IA (Tollemar et al 1995).

The efficacy of the antifungal prophylaxis oral solution of itraconazole as has been assessed in two reports on OLT recipients. A randomized, controlled trial of itraconazole in an oral solution (200 mg every $12 \mathrm{~h}$ ) versus intravenous or oral fluconazole (400 mg every $24 \mathrm{~h}$ ) documented no significant difference in the incidence of IA (Winston and Busuttil 2002).

On the other hand, the Spanish group GESITRA has communicated recently the preliminary results of a prospective, noncomparative, open label trial on antifungal prophylaxis with caspofungin in high-risk OLT recipients (Fortun et al 2007). Overall, caspofungin prophylaxis was successful in $87.8 \%$ of the patients. These results suggest promise for the prophylactic use of echinocandins in high risk OLT.

However, it is controversial the election of antifungal agent for prophylaxis in these patients. The high cost and the need of parenteral infusion limits the use of lipid formulations of AmB and caspofungin. Despite in vitro data suggesting that caspofungin in combination with calcineurin or TOR-inhibitors may have enhanced activity against Aspergillus, breakthrough infections in patients on caspofungin have been noted (Kontoyiannis et al 2003). The recommendations for prophylaxis against Aspergillus in OLT are a lipid formulation of $\mathrm{AmB}$, voriconazole or caspofungin, with a duration of 3-4 weeks or until resolution of risk factors. In heart transplant recipients routine antifungal prophylaxis is not warranted, but in patients deemed to be at high risk (Table 6), itraconazole at $400 \mathrm{mg}$ daily administered orally from day 5 after transplantation for 3 to 6 months is associated with a significantly lower incidence of IA (Munoz et al 2004).

Randomized studies in high-risk patients are needed to determine the efficacy of targeted antifungal prophylaxis for the prevention of IA. In the meantime, each centre needs to evaluate its own recipient risk factors and rates of IA to determine whether these strategies are appropriate for its patients (Biancofiore et al 2002).

In conclusion, targeted prophylaxis against Candida and Aspergillus spp. is recommended in all SOT. Fluconazole should be used for prophylaxis against Candida spp. unless the institution has a high rate of non-albicans infections; conversely, voriconazole is recomended for prophylaxis against Aspergillus spp. allthough its significant interactions with immunosuppressive agents could be a potential limiting factor.

\section{Targeted therapy of IFI in solid organ transplant patients}

With regard to the treatment, voriconazole, an extended spectrum highly lipophilic triazole with $98 \%$ oral bioavailability, is actually the first choice for initial therapy of IA in LT patients and other immunosuppressed hosts. Furthermore, the first experiences with LT patients also evidenced that continuous infusion of AmB is well tolerated, safe and efficient (Speich et al 2002). Other potentially effective therapies include lipid formulations of AmB and echinocandins. Combination therapy using a triazole and an echinocandin has been evaluated in SOT, with a significant reduction in mortality in those patients with renal failure and infected by A. fumigatus (Singh et al 2006a).

In conclusion, IFIs, especially immunocompromised and critical care patients, have become an excellent target for prophylactic, empiric, and pre-emptive therapy interventions due to high morbidity and mortality rates, an increasing incidence, and associated health care costs. Early diagnosis and treatment are associated with a better prognosis. In all cases the choice of antifungal drug must be based on the individual characteristics of the patient. A tailored therapy (de-escalation) must also be considered in the ICU setting. Furthermore, risk-adapted prophylaxis is the best option in hematological and SOT patients.

\section{Disclosure}

The authors report no conflicts of interest in this work.

\section{References}

Agresti MG, De Bernardis F, Mondello F, et al. 1994. Clinical and mycological evaluation of fluconazole in the secondary prophylaxis of esophageal candidiasis in AIDS patients. An open, multicenter study. Eur J Epidemiol, 10:17-22.

Akamatsu N, Sugawara Y, Kaneko J, et al. 2007. Preemptive treatment of fungal infection based on plasma $(1->3)$ beta-D-glucan levels after liver transplantation. Infection, 35:346-51. 
Alberti C, Brun-Buisson C, Burchardi H, et al. 2002. Epidemiology of sepsis and infection in ICU patients from an international multicentre cohort study. Intensive Care Med, 28:108-21.

Almirante B, Rodriguez D, Park BJ, et al. 2005. The Barcelona Candidemia Project Study Group. Epidemiology and predictors of mortality in cases of Candida bloodstream infection: results from population-based surveillance, Barcelona, Spain, from 2002 to 2003. J Clin Microbiol, 43:1829-35.

Altmannsberger P, Holler E, Andreesen R, et al. 2007. Amphotericin B deoxycholate: no significant advantage of a $24 \mathrm{~h}$ over a $6 \mathrm{~h}$ infusion schedule. J Antimicrob Chemother, 60:180-2.

Alvarez-Lerma F, Palomar M, Leon C, et al. 2003. Colonización y/o infección fúngica en unidades de cuidados intensivos. Estudio multicéntrico de 1.562 pacientes. Med Clin (Barc), 121:161-6.

Arnow PM, Carandang GC, Zabner R, et al. 1996. Randomized controlled trial of selective bowel decontamination for prevention of infections following liver transplantation. Clin Infect Dis, 22:997-1003.

Ascioglu S, Rex JH, de Pauw B, et al. 2002. Defining opportunistic invasive fungal infections in immunocompromised patients with cancer and hematopoietic stem cell transplants: an international consensus. Clin Infect Dis, 34:7-14.

Bates DW, Su L, Yu DT, et al. 2001. Mortality and costs of acute renal failure associated with amphotericin B therapy. Clin Infect Dis, 32:686-93.

Ben Abraham R, Keller N, Teodorovitch N, et al. Predictors of adverse outcome from candidal infection in a tertiary care hospital. $J$ Infect, 49:317-23.

Biancofiore G, Bindi ML, Baldassarri R, et al. 2002. Antifungal prophylaxis in liver transplant recipients: a randomized placebo-controlled study. Transpl Int, 15:341-7.

Blot SI, Vandewoude KH, Hoste EA, et al. 2002. Effects of nosocomial candidemia on outcomes of critically ill patients. Am J Med, 113:480-5.

Blumberg HM, Jarvis WR, Soucie JM, et al. 2001. Risk factors for candidal bloodstream infections in surgical intensive care unit patients: the NEMIS prospective multicenter study. The National Epidemiology of Mycosis Survey. Clin Infect Dis, 33:177-86.

Bow EJ. 2008. Considerations in the approach to invasive fungal infection in patients with haematological malignancies. $\mathrm{Br} J$ Haematol, 140:133-52.

Bow EJ, Laverdiere M, Lussier N, et al. 2002. Antifungal prophylaxis for severely neutropenic chemotherapy recipients: a meta analysis of randomized-controlled clinical trials. Cancer, 94:3230-46.

Caillot D, Thiebaut A, Herbrecht R, et al. 2007. Liposomal amphotericin B in combination with caspofungin for invasive aspergillosis in patients with hematologic malignancies: a randomized pilot study (Combistrat trial). Cancer, 110:2740-6.

Calandra T, Marchetti O. 2002. Antifungal prophylaxis for intensive care unit patients: let's fine tune it. Intensive Care Med, 28:1698-700.

Calvo V, Borro JM, Morales P, et al. 1999. Antifungal prophylaxis during the early postoperative period of lung transplantation. Valencia Lung Transplant Group. Chest, 115:1301-4.

Castroagudin JF, Ponton C, Bustamante M, et al. 2005. Prospective interventional study to evaluate the efficacy and safety of liposomal amphotericin B as prophylaxis of fungal infections in high-risk liver transplant recipients. Transplant Proc, 37:3965-7.

Chandrasekar PH, Sobel JD. 2006. Micafungin: a new echinocandin. Clin Infect Dis, 42:1171-8.

Corcoran TE, Venkataramanan R, Mihelc KM, et al. 2006. Aerosol deposition of lipid complex amphotericin-B (Abelcet) in lung transplant recipients. Am J Transplant, 6:2765-73.

Cordonnier C, Maury S, Ribaud P, et al. 2006. A grading system based on severity of infection to predict mortality in allogeneic stem cell transplant recipients. Transplantation, 82:86-92.

Cornely OA, Maertens J, Bresnik M, et al. 2007a. Liposomal amphotericin $B$ as initial therapy for invasive mold infection: a randomized trial comparing a high-loading dose regimen with standard dosing (AmBiLoad trial). Clin Infect Dis, 44:1289-97.
Cornely OA, Maertens J, Winston DJ, et al. 2007b. Posaconazole vs fluconazole or itraconazole prophylaxis in patients with neutropenia. N Engl J Med, 356:348-59.

Covarrubias MB, Milstone AB. 2005. An overview of fungal prophylaxis in lung transplantation. Curr Opin Organ Transplant, 10:227-32.

Cruciani M, de Lalla F, Mengoli C. 2005. Prophylaxis of Candida infections in adult trauma and surgical intensive care patients: a systematic review and meta-analysis. Intensive Care Med, 31:1479-87.

Cruciani M, Mengoli C, Malena M, et al. 2006. Antifungal prophylaxis in liver transplant patients: a systematic review and meta-analysis. Liver Transpl, 12:850-8.

De Pauw BE. 2005. Between over- and undertreatment of invasive fungal disease. Clin Infect Dis, 41:1251-3.

De Waele JJ, Vogelaers D, Blot S, et al. 2003. Fungal infections in patients with severe acute pancreatitis and the use of prophylactic therapy. Clin Infect Dis, 37:208-13.

Dimopoulos G, Ntziora F, Rachiotis G, et al. 2008. Candida albicans versus non-albicans intensive care unit-acquired bloodstream infections: differences in risk factors and outcome. Anesth Analg, 106:523-9.

Dimopoulos G, Piagnerelli M, Berre J, et al. 2004. Post mortem examination in the intensive care unit: still useful? Intensive Care Med, 30:2080-5.

DiNubile MJ, Lupinacci RJ, Strohmaier KM, et al. 2007. Invasive candidiasis treated in the intensive care unit: observations from a randomized clinical trial. J Crit Care, 22:237-44.

Drew R. 2006. Potential role of aerosolized amphotericin B formulations in the prevention and adjunctive treatment of invasive fungal infections. Int J Antimicrob Agents, 27(Suppl 1):36-44.

Drew RH, Dodds AE, Benjamin DK Jr, et al. 2004. Comparative safety of amphotericin B lipid complex and amphotericin B deoxycholate as aerosolized antifungal prophylaxis in lung-transplant recipients. Transplantation, 77:232-7.

Echaniz-Quintana A, Pita-Fernandez S, Otero-Ferreiro A, et al. 2004. Risk factors associated with invasive fungal infection in orthotopic liver transplantation. Med Clin (Barc), 122:444-8.

Eggimann P, Francioli P, Bille J, et al.1999. Fluconazole prophylaxis prevents intra-abdominal candidiasis in high-risk surgical patients. Crit Care Med, 27:1066-72.

Eriksson U, Seifert B, Schaffner A. 2001. Comparison of effects of amphotericin B deoxycholate infused over 4 or 24 hours: randomised controlled trial. $B M J, 322: 579-82$.

Falagas ME, Apostolou KE, Pappas VD. 2006. Attributable mortality of candidemia: a systematic review of matched cohort and case-control studies. Eur J Clin Microbiol Infect Dis, 25:419-25.

Florent M, Katsahian S, Vekhoff A, et al. 2006. Prospective evaluation of a polymerase chain reaction-ELISA targeted to Aspergillus fumigatus and Aspergillus flavus for the early diagnosis of invasive aspergillosis in patients with hematological malignancies. $J$ Infect Dis, 193:741-7.

Fluckiger U, Marchetti O, Bille J, et al. 2006. Treatment options of invasive fungal infections in adults. Swiss Med Wkly, 136:447-63.

Fortun J, Martin-Davila P, Moreno S, et al. 2003. Prevention of invasive fungal infections in liver transplant recipients: the role of prophylaxis with lipid formulations of amphotericin B in high-risk patients. $J$ Antimicrob Chemother, 52:813-9.

Fortun J, Montejo M, Martin-Davila P, et al. 2007. Prospective, multicentre study of caspofungin for prophylaxis in high-risk liver transplantation [abstract]. 17th European Congress of Clinical Microbiology and Infectious Diseases. ICC, Munich, Germany, March 31-April 3. pp. 1733-463.

Garbino J, Lew DP, Romand JA, et al. 2002. Prevention of severe Candida infections in nonneutropenic, high-risk, critically ill patients: a randomized, double-blind, placebo-controlled trial in patients treated by selective digestive decontamination. Intensive Care Med, 28:1708-17.

Garey KW, Rege M, Pai MP, et al. 2006. Time to initiation of fluconazole therapy impacts mortality in patients with candidemia: a multi-institutional study. Clin Infect Dis, 43:25-31. 
Garnacho-Montero J, León C, Almirante B, et al. 2005. Recomendaciones terapéuticas para infecciones fúngicas en el paciente crítico no neutropénico. Conferencia de consenso. Conclusiones. Med Intensiva, 3(Suppl 1):43-52.

Greene R. 2005. The radiological spectrum of pulmonary aspergillosis. Med Mycol, 43(Suppl 1):S147-S154.

Hagerman JK, Hancock KE, Klepser ME. 2006. Aerosolised antibiotics: a critical appraisal of their use. Expert Opin Drug Deliv, 3:71-86.

Hellinger WC, Bonatti H, Yao JD, et al. 2005. Risk stratification and targeted antifungal prophylaxis for prevention of aspergillosis and other invasive mold infections after liver transplantation. Liver Transpl, 11:656-62.

Hellinger WC, Yao JD, Alvarez S, et al. 2002. A randomized, prospective, double-blinded evaluation of selective bowel decontamination in liver transplantation. Transplantation, 73:1904-9.

Herbrecht R. 2002. Improving the outcome of invasive aspergillosis: new diagnostic tools and new therapeutic strategies. Ann Hematol, 81(Suppl 2):S52-S53.

Herbrecht R, Denning DW, Patterson TF, et al. 2002. Voriconazole versus amphotericin B for primary therapy of invasive aspergillosis. $N$ Engl $J$ Med, 347:408-15.

Hjortrup A, Rasmussen A, Hansen BA, et al. 1997. Early bacterial and fungal infections in liver transplantation after oral selective bowel decontamination. Transplant Proc, 29:3106-10.

Hope WW, Walsh TJ, Denning DW. 2005. Laboratory diagnosis of invasive aspergillosis. Lancet Infect Dis, 5:609-22.

Hughes WT, Armstrong D, Bodey GP, et al. 2002. 2002 guidelines for the use of antimicrobial agents in neutropenic patients with cancer. Clin Infect Dis, 34:730-51.

Husain S, Paterson DL, Studer S, et al. 2006a. Voriconazole prophylaxis in lung transplant recipients. Am J Transplant, 6:3008-16.

Husain S, Tollemar J, Dominguez EA, et al. 2003. Changes in the spectrum and risk factors for invasive candidiasis in liver transplant recipients: prospective, multicenter, case-controlled study. Transplantation, 75:2023-9.

Husain S, Zaldonis D, Kusne S, et al. 2006b. Variation in antifungal prophylaxis strategies in lung transplantation. Transpl Infect Dis, $8: 213-8$.

Ibanez-Nolla J, Nolla-Salas M, Leon MA, et al. 2004. Early diagnosis of candidiasis in non-neutropenic critically ill patients. $J$ Infect, 48:181-92.

Jarque I, Salavert M, Roma E, et al. 2004. Hospital Universitario La Fe Guide to the prophylaxis and treatment of fungal infections in immunodepressed patients or in patients requiring special care. Rev Esp Quimioter, 17:357-89.

Johnson JR. 2004. Reduction of nephrotoxicity associated with amphotericin B deoxycholate. Clin Infect Dis, 38:303-7.

Jorgensen KJ, Gotzsche PC, Johansen HK. 2006. Voriconazole versus amphotericin B in cancer patients with neutropenia. Cochrane Database Syst Rev, 1:CD004707.

Kanda Y, Yamamoto R, Chizuka A, et al. 2000. Prophylactic action of oral fluconazole against fungal infection in neutropenic patients. A metaanalysis of 16 randomized, controlled trials. Cancer, 89:1611-25.

Klingspor L, Tornqvist E, Johansson A, et al. 2004. A prospective epidemiological survey of candidaemia in Sweden. Scand J Infect Dis, 36:52-5.

Kontoyiannis DP, Lewis RE. 2004. Toward more effective antifungal therapy: the prospects of combination therapy. $\mathrm{Br} J$ Haematol, 126:165-75.

Kontoyiannis DP, Lewis RE, Osherov N, et al. 2003. Combination of caspofungin with inhibitors of the calcineurin pathway attenuates growth in vitro in Aspergillus species. J Antimicrob Chemother, 51:313-6.

Kullberg BJ, Sobel JD, Ruhnke M, et al. 2005. Voriconazole versus a regimen of amphotericin B followed by fluconazole for candidaemia in non-neutropenic patients: a randomised non-inferiority trial. Lancet, $366: 1435-42$.

Kuse ER, Chetchotisakd P, da Cunha CA, et al. 2007. Micafungin versus liposomal amphotericin B for candidaemia and invasive candidosis: a phase III randomised double-blind trial. Lancet, 369:1519-27.
Leather HL, Wingard JR. 2006. New strategies of antifungal therapy in hematopoietic stem cell transplant recipients and patients with hematological malignancies. Blood Rev, 20:267-87.

Leleu G, Aegerter P, Guidet B. 2002. Systemic candidiasis in intensive care units: a multicenter, matched-cohort study. J Crit Care, 17:168-75.

Leon C, Ruiz-Santana S, Saavedra P, et al. 2006. A bedside scoring system ("Candida score") for early antifungal treatment in nonneutropenic critically ill patients with Candida colonization. Crit Care Med, 34:730-7.

Lowry CM, Marty FM, Vargas SO, et al. 2007. Safety of aerosolized liposomal versus deoxycholate amphotericin $\mathrm{B}$ formulations for prevention of invasive fungal infections following lung transplantation: a retrospective study. Transpl Infect Dis, 9:121-5.

Lumbreras C, Cuervas-Mons V, Jara P, et al. 1996. Randomized trial of fluconazole versus nystatin for the prophylaxis of Candida infection following liver transplantation. $J$ Infect Dis, 174:583-8.

Maertens J, Deeren D, Dierickx D, et al. 2006. Preemptive antifungal therapy: still a way to go. Curr Opin Infect Dis, 19:551-6.

Maertens J, Theunissen K, Verhoef G, et al. 2005. Galactomannan and computed tomography-based preemptive antifungal therapy in neutropenic patients at high risk for invasive fungal infection: a prospective feasibility study. Clin Infect Dis, 41:1242-50.

Maertens J, Verhaegen J, Lagrou K, et al. 2001. Screening for circulating galactomannan as a noninvasive diagnostic tool for invasive aspergillosis in prolonged neutropenic patients and stem cell transplantation recipients: a prospective validation. Blood, 97:1604-10.

Magill SS, Dropulic LK. 2006. Antifungal prophylaxis in transplant recipients: where do we go from here? Transpl Infect Dis, 8:187-9.

Marik PE. 2006. Fungal infections in solid organ transplantation. Expert Opin Pharmacother, 7:297-305.

Marr KA, Boeckh M, Carter RA, et al. 2004a. Combination antifungal therapy for invasive aspergillosis. Clin Infect Dis, 39:797-802.

Marr KA, Crippa F, Leisenring W, et al. 2004b. Itraconazole versus fluconazole for prevention of fungal infections in patients receiving allogeneic stem cell transplants. Blood, 103:1527-33.

Mattiuzzi GN, Alvarado G, Giles FJ, et al. 2006. Open-label, randomized comparison of itraconazole versus caspofungin for prophylaxis in patients with hematologic malignancies. Antimicrob Agents Chemother, 50:143-7.

Meersseman W, Lagrou K, Maertens J, et al. 2008. Galactomannan in bronchoalveolar lavage fluid: a tool for diagnosing aspergillosis in intensive care unit patients. Am J Respir Crit Care Med, 177:27-34.

Mennink-Kersten MA, Klont RR, Warris A, et al. 2004. Bifidobacterium lipoteichoic acid and false ELISA reactivity in aspergillus antigen detection. Lancet, 363:325-7.

Metcalf SC, Dockrell DH. 2007. Improved outcomes associated with advances in therapy for invasive fungal infections in immunocompromised hosts. J Infect, 55:287-99.

Millon L, Piarroux R, Deconinck E, et al. 2005. Use of real-time PCR to process the first galactomannan-positive serum sample in diagnosing invasive aspergillosis. J Clin Microbiol, 43:5097-101.

Mohammad RA, Klein KC. 2006. Inhaled amphotericin B for prophylaxis against invasive Aspergillus infections. Ann Pharmacother, 40:2148-54.

Monforte V, Roman A, Gavalda J, et al. 2005. Prophylaxis for Aspergillus infection in lung transplantation: Pharmacokinetics, safety and efficacy [abstract]. J Heart Lung Transplant.

Monforte V, Roman A, Gavalda J, et al. 2003. Nebulized amphotericin B concentration and distribution in the respiratory tract of lung-transplanted patients. Transplantation, 75:1571-4.

Mora-Duarte J, Betts R, Rotstein C, et al. 2002. Comparison of caspofungin and amphotericin B for invasive candidiasis. $N$ Engl J Med, 347:2020-9.

Moragues MD, Ortiz N, Iruretagoyena JR, et al. 2004. Evaluation of a new commercial test (Candida albicans IFA $\operatorname{IgG}$ ) for the serodiagnosis of invasive candidiasis. Enferm Infecc Microbiol Clin, 22:83-8. 
Morgan J, Meltzer MI, Plikaytis BD, et al. 2005. Excess mortality, hospital stay, and cost due to candidemia: a case-control study using data from population-based candidemia surveillance. Infect Control Hosp Epidemiol, 26:540-7.

Morrell M, Fraser VJ, Kollef MH. 2005. Delaying the empiric treatment of Candida bloodstream infection until positive blood culture results are obtained: a potential risk factor for hospital mortality. Antimicrob Agents Chemother, 49:3640-5.

Munoz P, Rodriguez C, Bouza E, et al. 2004. Risk factors of invasive aspergillosis after heart transplantation: protective role of oral itraconazole prophylaxis. Am J Transplant, 4:636-43.

Nolla-Salas J, Sitges-Serra A, Leon-Gil C, et al. 1997. Candidemia in nonneutropenic critically ill patients: analysis of prognostic factors and assessment of systemic antifungal therapy. Study Group of Fungal Infection in the ICU. Intensive Care Med, 23:23-30.

Odabasi Z, Mattiuzzi G, Estey E, et al. 2004. Beta-D-glucan as a diagnostic adjunct for invasive fungal infections: validation, cutoff development, and performance in patients with acute myelogenous leukemia and myelodysplastic syndrome. Clin Infect Dis, 39:199-205.

Ostrosky-Zeichner L, Alexander BD, Kett DH, et al. 2005. Multicenter clinical evaluation of the $(1->3)$ beta-D-glucan assay as an aid to diagnosis of fungal infections in humans. Clin Infect Dis, 41:654-9.

Ostrosky-Zeichner L, Sable C, Sobel J, et al. 2007. Multicenter retrospective development and validation of a clinical prediction rule for nosocomial invasive candidiasis in the intensive care setting. Eur J Clin Microbiol Infect Dis, 26:271-6.

Palmer SM, Drew RH, Whitehouse JD, et al. 2001. Safety of aerosolized amphotericin B lipid complex in lung transplant recipients. Transplantation, 72:545-8.

Pappas PG, Rex JH, Sobel JD, et al. 2004. Guidelines for treatment of candidiasis. Clin Infect Dis, 38:161-89.

Pappas PG, Rotstein CM, Betts RF, et al. 2007. Micafungin versus caspofungin for treatment of candidemia and other forms of invasive candidiasis. Clin Infect Dis, 45:883-93.

Parkins MD, Sabuda DM, Elsayed S, et al. 2007. Adequacy of empirical antifungal therapy and effect on outcome among patients with invasive Candida species infections. J Antimicrob Chemother, 60:613-8.

Pazos C, Moragues MD, Quindos G, et al. 2006. Diagnostic potential of (1,3)-beta-D-glucan and anti-Candida albicans germ tube antibodies for the diagnosis and therapeutic monitoring of invasive candidiasis in neutropenic adult patients. Rev Iberoam Micol, 23:209-15.

Pazos C, Ponton J, del Palacio A. 2005. Contribution of (1 - >3)-betaD-glucan chromogenic assay to diagnosis and therapeutic monitoring of invasive aspergillosis in neutropenic adult patients: a comparison with serial screening for circulating galactomannan. J Clin Microbiol, 43:299-305.

Peleg AY, Woods ML. 2004. Continuous and $4 \mathrm{~h}$ infusion of amphotericin B: a comparative study involving high-risk haematology patients. J Antimicrob Chemother, 54:803-8.

Pelz RK, Hendrix CW, Swoboda SM, et al. 2001. Double-blind placebocontrolled trial of fluconazole to prevent candidal infections in critically ill surgical patients. Ann Surg, 233:542-8.

Perkins JD. 2007. Use of Aspergillus galactomannan enzyme-linked immunosorbent assay (ELISA) in liver transplant patients. Liver Transpl, 13:304-5.

Petri MG, Konig J, Moecke HP, et al. 1997. Epidemiology of invasive mycosis in ICU patients: a prospective multicenter study in 435 nonneutropenic patients. Paul-Ehrlich Society for Chemotherapy, Divisions of Mycology and Pneumonia Research. Intensive Care Med, 23:317-25.

Pfaller MA, Jones RN, Doern GV, et al. 2000. Bloodstream infections due to Candida species: SENTRY antimicrobial surveillance program in North America and Latin America, 1997-1998. Antimicrob Agents Chemother, 44:747-51.

Pfeiffer CD, Fine JP, Safdar N. 2006. Diagnosis of invasive aspergillosis using a galactomannan assay: a meta-analysis. Clin Infect Dis, 42:1417-27.
Phillips P, Shafran S, Garber G, et al. 1997. Multicenter randomized trial of fluconazole versus amphotericin B for treatment of candidemia in non-neutropenic patients. Canadian Candidemia Study Group. Eur J Clin Microbiol Infect Dis, 16:337-45.

Piarroux R, Grenouillet F, Balvay P, et al. 2004. Assessment of preemptive treatment to prevent severe candidiasis in critically ill surgical patients. Crit Care Med, 32:2443-9.

Pickering JW, Sant HW, Bowles CA, et al. 2005. Evaluation of a (1->3)beta-D-glucan assay for diagnosis of invasive fungal infections. J Clin Microbiol, 43:5957-62.

Playford EG, Webster AC, Sorell TC, et al. 2004. Antifungal agents for preventing fungal infections in solid organ transplant recipients. Cochrane Database Syst Rev, 3:CD004291.

Playford EG, Webster AC, Sorrell TC, et al. 2006. Antifungal agents for preventing fungal infections in non-neutropenic critically ill and surgical patients: systematic review and meta-analysis of randomized clinical trials. J Antimicrob Chemother, 57:628-38.

Ponton J, del Palacio A. 2007. Advances and limitations in the early diagnosis of invasive yeast infections. Rev Iberoam Micol, 24:181-6.

Ponton J, Quindos G, Arilla MC, et al. 1994. Simplified adsorption method for detection of antibodies to Candida albicans germ tubes. J Clin Microbiol, 32:217-9.

Puzniak L, Teutsch S, Powderly W, et al. 2004. Has the epidemiology of nosocomial candidemia changed? Infect Control Hosp Epidemiol, 25:628-33.

Quindos G, Moragues MD, Ponton J. 2004. Is there a role for antibody testing in the diagnosis of invasive candidiasis? Rev Iberoam Micol, 21:10-4.

Reboli AC, Rotstein C, Pappas PG, et al. 2007. Anidulafungin versus fluconazole for invasive candidiasis. N Engl J Med, 356:2472-82.

Reichenspurner H, Gamberg P, Nitschke M, et al. 1997. Significant reduction in the number of fungal infections after lung-, heart-lung, and heart transplantation using aerosolized amphotericin B prophylaxis. Transplant Proc, 29:627-8.

Rex JH, Bennett JE, Sugar AM, et al. 1994. A randomized trial comparing fluconazole with amphotericin B for the treatment of candidemia in patients without neutropenia. Candidemia Study Group and the National Institute. $N$ Engl J Med, 331:1325-30.

Rijnders BJ, Cornelissen JJ, Slobbe L, et al. 2008. Aerosolized liposomal amphotericin B for the prevention of invasive pulmonary aspergillosis during prolonged neutropenia: a randomized, placebo-controlled trial. Clin Infect Dis, 46:1401-8.

Schneemann M, Bachli EB. 2004. Continuous infusion of amphotericin B deoxycholate: a cost-effective gold standard for therapy of invasive fungal infections? Clin Infect Dis, 38:303-4.

Sendid B, Cotteau A, Francois N, et al. 2006. Candidaemia and antifungal therapy in a French University Hospital: rough trends over a decade and possible links. BMC Infect Dis, 6:80.

Sharpe MD, Ghent C, Grant D, et al. 2003. Efficacy and safety of itraconazole prophylaxis for fungal infections after orthotopic liver transplantation: a prospective, randomized, double-blind study. Transplantation, 76:977-83.

Shorr AF, Chung K, Jackson WL, et al. 2005. Fluconazole prophylaxis in critically ill surgical patients: a meta-analysis. Crit Care Med, 33:1928-35.

Silveira FP, Husain S. 2007. Fungal infections in solid organ transplantation. Med Mycol, 45:305-20.

Singh N. 2000. Antifungal prophylaxis for solid organ transplant recipients: seeking clarity amidst controversy. Clin Infect Dis, 31:545-53.

Singh N. 2004. Antifungal prophylaxis in solid-organ transplant recipients: considerations for clinical trial design. Clin Infect Dis, 39(Suppl 4): S200-S206

Singh N. 2005. Invasive aspergillosis in organ transplant recipients: new issues in epidemiologic characteristics, diagnosis, and management. Med Mycol, 43(Suppl 1):S267-S270.

Singh N, Alexander BD, Lortholary O, et al. 2007. Cryptococcus neoformans in organ transplant recipients: impact of calcineurin-inhibitor agents on mortality. J Infect Dis, 195:756-64. 
Singh N, Husain S. 2003. Aspergillus infections after lung transplantation: clinical differences in type of transplant and implications for management. J Heart Lung Transplant, 22:258-66.

Singh N, Limaye AP, Forrest G, et al. 2006a. Combination of voriconazole and caspofungin as primary therapy for invasive aspergillosis in solid organ transplant recipients: a prospective, multicenter, observational study. Transplantation, 81:320-6.

Singh N, Limaye AP, Forrest G, et al. 2006b. Late-onset invasive aspergillosis in organ transplant recipients in the current era. Med Mycol, 44:445-9.

Singh N, Paterson DL. 2005. Aspergillus infections in transplant recipients. Clin Microbiol Rev, 18:44-69.

Singh N, Paterson DL, Gayowski T, et al. 2001. Preemptive prophylaxis with a lipid preparation of amphotericin B for invasive fungal infections in liver transplant recipients requiring renal replacement therapy. Transplantation, 71:910-3.

Singh N, Pruett TL, Houston S, et al. 2006c. Invasive aspergillosis in the recipients of liver retransplantation. Liver Transpl, 12:1205-9.

Solé A, Morant P, Salavert M, et al. 2005. Aspergillus infections in lung transplant recipients: risk factors and outcome. Clin Microbiol Infect, 11:359-65.

Solé A, Nieto M. 2007. Nebulized antifungal prophylaxis:Role of amphotericin B lipid complex. Med Intensiva, 5:64-70.

Solé A, Salavert M. 2007. Voriconazole for the therapy of mycoses in recipients of solid organ transplants. Rev Iberoam Micol, 24:217-22.

Solé A, Salavert M. 2008. Fungal infections after lung transplantation. Transplant Rev (Orlando), 22:89-104.

Speich R, Dutly A, Naef R, et al. 2002. Tolerability, safety and efficacy of conventional amphotericin B administered by 24-hour infusion to lung transplant recipients. Swiss Med Wkly, 132:455-8.

Sulahian A, Touratier S, Ribaud P. 2003. False positive test for aspergillus antigenemia related to concomitant administration of piperacillin and tazobactam. N Engl J Med, 349:2366-7.

Tollemar J, Hockerstedt K, Ericzon BG, et al. 1995. Liposomal amphotericin B prevents invasive fungal infections in liver transplant recipients. A randomized, placebo-controlled study. Transplantation, 59:45-50.

Tortorano AM, Peman J, Bernhardt H, et al. 2004. Epidemiology of candidaemia in Europe: results of 28-month European Confederation of Medical Mycology (ECMM) hospital-based surveillance study. Eur J Clin Microbiol Infect Dis, 23:317-22.

Ullmann AJ, Heussel CP, Cornely OA. 2002. Voriconazole versus liposomal amphotericin B for empirical antifungal therapy. $N$ Engl J Med, 346:1745-7.

Ullmann AJ, Lipton JH, Vesole DH, et al. 2007. Posaconazole or fluconazole for prophylaxis in severe graft-versus-host disease. $N$ Engl $J$ Med, 356:335-47. van Burik JA. 2005. Role of new antifungal agents in prophylaxis of mycoses in high risk patients. Curr Opin Infect Dis, 18:479-83.

van Burik JA, Ratanatharathorn V, Stepan DE, et al. 2004. Micafungin versus fluconazole for prophylaxis against invasive fungal infections during neutropenia in patients undergoing hematopoietic stem cell transplantation. Clin Infect Dis, 39:1407-16.

Walsh TJ, Finberg RW, Arndt C, et al. 1999. Liposomal amphotericin B for empirical therapy in patients with persistent fever and neutropenia. National Institute of Allergy and Infectious Diseases Mycoses Study Group. N Engl J Med, 340:764-71.

Walsh TJ, Pappas P, Winston DJ, et al. 2002. Voriconazole compared with liposomal amphotericin B for empirical antifungal therapy in patients with neutropenia and persistent fever. $N$ Engl J Med, 346:225-34.

Walsh TJ, Teppler H, Donowitz GR, et al. 2004. Caspofungin versus liposomal amphotericin B for empirical antifungal therapy in patients with persistent fever and neutropenia. $N$ Engl $\mathrm{J} \mathrm{Med}$, 351:1391-402.

Wiesner RH, Hermans PE, Rakela J, et al. 1988. Selective bowel decontamination to decrease gram-negative aerobic bacterial and Candida colonization and prevent infection after orthotopic liver transplantation. Transplantation, 45:570-4.

Wingard JR, Carter SL, Walsh TJ, et al. 2007. Results of a randomized, double-blind trial of fluconazole vs. voriconazole for the prevention of invasive fungal infections in 600 allogeneic blood and marrow transplant patients. Blood, 110:163.

Winston DJ, Busuttil RW. 2002. Randomized controlled trial of oral itraconazole solution versus intravenous/oral fluconazole for prevention of fungal infections in liver transplant recipients. Transplantation, 74:688-95

Winston DJ, Pakrasi A, Busuttil RW. 1999. Prophylactic fluconazole in liver transplant recipients. A randomized, double-blind, placebo-controlled trial. Ann Intern Med, 131:729-37.

Wong-Beringer A, Lambros MP, Beringer PM, et al. 2005. Suitability of caspofungin for aerosol delivery: physicochemical profiling and nebulizer choice. Chest, 128:3711-16.

Zaragoza R, Peman J. 2006. Invasive fungal infections in critically ill patients: different therapeutic options and a uniform strategy. Rev Iberoam Micol, 23:59-63.

Zaragoza R, Peman J, Ramirez P, et al. 2006. Clinical and management utility of Candida germ tube antibody detection in critically ill patients. Preliminary data [abstract]. 46th Interscience Conference on Antimicrobial Agents and Chemotherapy, San Francisco, CA, Sept 27-30. M-1618. 